\title{
Micro/Mesoporous Zeolitic Composites: Recent Developments in Synthesis and Catalytic Applications
}

\author{
Xuan Hoan $\mathrm{Vu}^{1,2, *}$, Udo Armbruster ${ }^{3}$ and Andreas Martin ${ }^{3, *}$ \\ 1 Department for Management of Science and Technology Development, Ton Duc Thang University, \\ Ho Chi Minh City 700000, Vietnam \\ 2 Faculty of Applied Sciences, Ton Duc Thang University, Ho Chi Minh City 700000, Vietnam \\ 3 Leibniz-Institut für Katalyse e.V. an der Universität Rostock, Albert-Einstein-Straße 29a, 18059 Rostock, \\ Germany; udo.armbruster@catalysis.de \\ * Correspondence: vuxuanhoan@tdt.edu.vn (X.H.V.); andreas.martin@catalysis.de (A.M.); \\ Tel.: +84-8-3776-0656 (X.H.V.); +49-381-1281-5146 (A.M.)
}

Academic Editor: Keith Hohn

Received: 27 October 2016; Accepted: 11 November 2016; Published: 29 November 2016

\begin{abstract}
Micro/mesoporous zeolitic composites (MZCs) represent an important class of hierarchical zeolitic materials that have attracted increasing attention in recent years. By introducing an additional mesoporous phase interconnected with the microporosity of zeolites, a hierarchical porous system of MZCs is formed which facilitates molecular transport while preserving the intrinsic catalytic properties of zeolites. Thus, these materials offer novel perspectives for catalytic applications. Over the years, numerous synthesis strategies toward the formation of MZCs have been realized and their catalytic applications have been reported. In this review, the three main synthesis routes, namely direct synthesis using zeolite precursors, recrystallization of zeolites, and zeolitization of preformed mesoporous materials are thoroughly discussed, with focus on prior works and the most recent developments along with prominent examples given from the literature. In addition, the significant improvement in the catalytic properties of MZCs in a wide range of industrially relevant reactions is presented through several representative cases. Some perspectives for the future development of MZCs are also given.
\end{abstract}

Keywords: zeolite composites; hierarchical zeolites; micro/mesoporous zeolites; mesoporous materials; catalytic cracking; alkylation of aromatics; hydroconversion; methanol-to-hydrocarbons

\section{Introduction}

Zeolites are crystalline aluminosilicates that consist of $\mathrm{SiO}_{4}$ and $\mathrm{AlO}_{4}$ tetrahedra as primary building units, connected by sharing one oxygen atom between two tetrahedra to form $3 \mathrm{D}$ frameworks with uniform pore sizes of molecular dimensions (typically $0.25-1 \mathrm{~nm}$ ) [1]. Currently more than 200 zeolite structures have been defined by the International Zeolite Association (IZA) [2]. Among them, about 20 zeolites such as Y (FAU), ZSM-5 (MFI), mordenite (MOR), beta (BEA), MCM-22 (MWW) etc. have been widely used as heterogeneous catalysts in a good number of industrial processes, e.g., fluid catalytic cracking (FCC), alkylation, methanol-to-hydrocarbons (MTH), and hydroconversion processes [3-7]. The success of zeolites in catalysis primarily stems from their outstanding properties including crystallinity, large inner surface area, superior hydrothermal stability, tunable acidic properties, and well-defined pore sizes with shape-selectivity. Nevertheless, zeolite catalysts retain one major drawback. As one side effect of the micropores, they often suffer from diffusion limitations particularly for large molecules. The restricted access and slow molecular transport to and from active acid sites confined in the zeolite crystal (known as "configurational" diffusion) lower the effectiveness of the zeolite catalyst (Figure 1). Furthermore, this limited 
mass-transfer may also cause pore blocking by large molecules or by coke-like deposit formation which contributes to the catalyst deactivation [8-10].
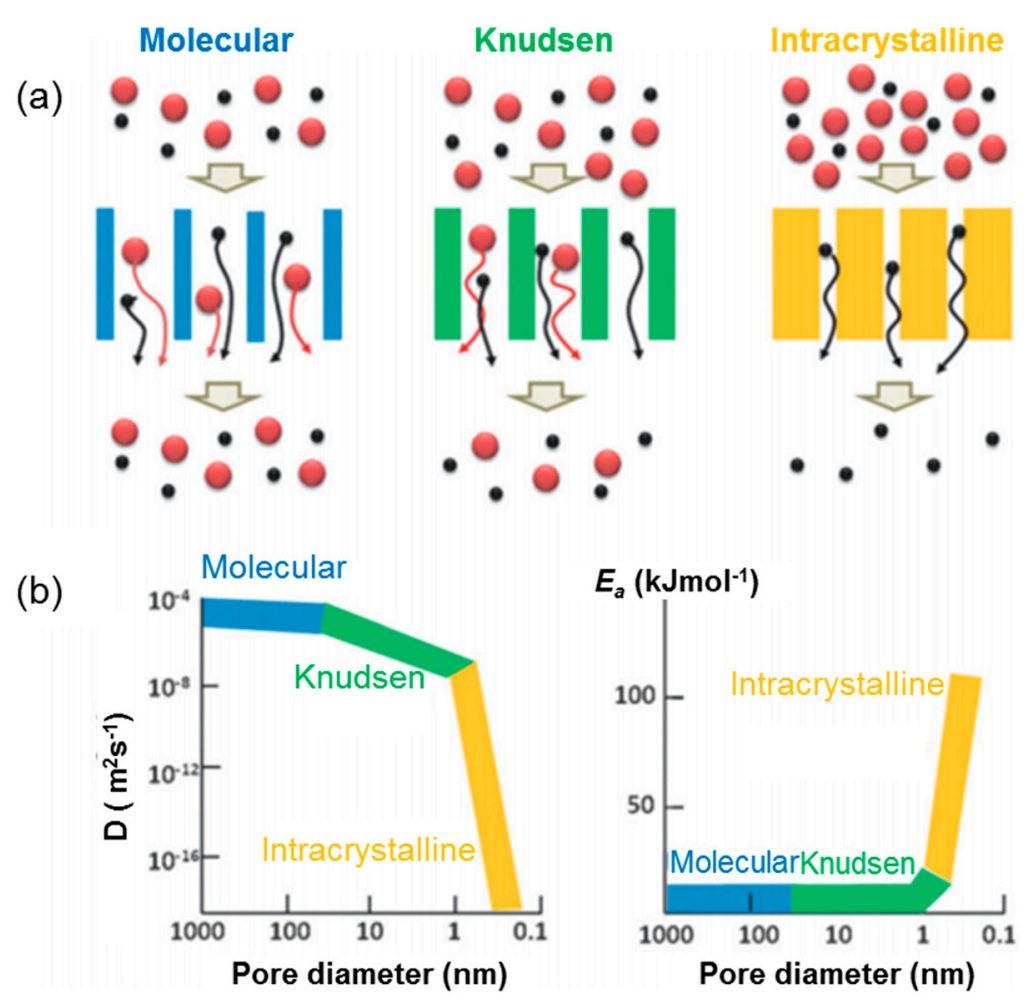

Figure 1. (a) Effect of pore sizes on the diffusion of large (red) and small (black) molecules within macropores (in blue, left), mesopores (in green, middle) and micropores (in yellow, right); (b) Effect of pore diameter on molecular diffusivity $(\mathrm{D}$, left $)$ and energy of activation $\left(\mathrm{E}_{\mathrm{a}}\right.$, right) in different diffusion regimes. Reproduced with permission from [8]. Copyright Royal Society of Chemistry, 2016.

On the other hand, the discovery of ordered mesoporous materials (OMMs) such as MCM- 41 or SBA-15 has brought a promising opportunity for moving the zeolite catalysis to the mesoscale [11,12]. With regular mesopores in the range of 2-30 nm, the diffusion regime in OMMs is typically Knudsen diffusion, whose diffusivity is several orders of magnitude higher than that of "configurational" diffusion inside micropores of the zeolite (see Figure 1). Unfortunately, OMMs fail to mimic the key characteristics of zeolites, i.e., high hydrothermal stability and strong intrinsic acidity owing to the non-crystalline nature of mesopore walls, which severely hinder their practical applications [13-15]. Hence, it is extremely desirable to design hierarchical zeolitic materials that couple the advantages of both mesoporous materials and microporous crystalline zeolites.

Over the past decades, a huge amount of hierarchical zeolitic materials have been realized and they can be broadly classified into two different types of materials: hierarchical zeolites and zeolite composites. Hierarchical zeolites (HZs) show pure zeolite phases in which a large fraction of mesoporosity is introduced in combination with genuine microporosity. This can be achieved by either introducing intracrystalline mesoporosity into zeolite crystals (mesoporous zeolites) or inducing intercrystalline mesoporosity between the intergrown nano-sized zeolite crystals (nano-zeolites). Zeolite composites, also known as micro/mesoporous zeolitic composites (MZCs) contain at least an additional mesoporous material acting as a composite partner for the zeolite phase (Figure 2). 
Hierarchical zeolitic materials

\begin{tabular}{ccc}
\hline \multicolumn{2}{c}{ Hierarchical zeolites (HZs) } & $\begin{array}{c}\text { Micro/mesoporous zeolitic } \\
\text { composites (MZCs) }\end{array}$ \\
\hline $\begin{array}{c}\text { Mesoporous zeolites } \\
>1 \mu \mathrm{m}\end{array}$ & Nanosized zeolites & Zeolite composites \\
Intracrystalline \\
mesopores
\end{tabular}

Figure 2. Categorization of hierarchical zeolitic materials that couple the advantages of both mesoporous materials and microporous crystalline zeolites. Adapted with permission from [10]. Copyright Royal Society of Chemistry, 2008.

To maximize the benefits of the bimodal porous system in catalyzed reactions, it is vital that the various domains of porosity should be interconnected to fulfil a distinct function: the micropores provide a high active surface area, the access to which is enhanced by the newly introduced mesopores $[10,16,17]$. Consequently, the design of hierarchical zeolitic materials for catalytic applications requires the introduction of mesoporosity in harmony with the existing microporous system. In recent years, there has been a rapid development in synthesis and applications of hierarchical zeolitic materials. Many excellent reviews highlighting various aspects of the latest progress in this field have been published $[6,8-10,13,14,16-29]$. It should be noted that most of them have focused on hierarchical zeolites (HZs). The topics concerning MZCs have been scarcely reviewed in the literature though numerous studies have been published on MZCs. In this context, the present review aims at providing an account of the recent developments of MZCs with emphasis on synthesis strategies and catalytic applications.

\section{Synthesis Strategies of Micro/Mesoporous Zeolitic Composites}

In order to form a hierarchical pore system within MZCs, the mesoporous phase has to be interconnected with the microporous phase. In this sense, the simple mechanical mixture of zeolites and mesoporous materials is not regarded as a MZC. Today, various synthesis strategies have been developed for designing MZCs with improved catalytic properties which can be divided into three main groups: (i) direct synthesis using zeolite precursors; (ii) recrystallization of zeolite crystals; (iii) zeolitization of preformed mesoporous materials. The sections below give a summary on the progress of these synthesis strategies. Attention is centered on the pioneering works and the most recent developments.

\subsection{Direct-Synthesis Using Zeolite Precursors}

The use of zeolite precursors, also known as zeolite nanoseeds or protozeolitic nanoparticles for preparation of MZCs in a two-step process perhaps represents the most extensively studied approach. In this method, zeolite precursors are first prepared by shortening the hydrothermal treatment time required for the evolution of classical zeolite crystals and subsequent assembly of these precursors in the presence of surfactants to form mesostructures. This idea was first realized by Pinnavaia et al. [30] in 2000 by using faujasitic zeolite (FAU) seeds to assemble with cetyltrimethylammonium bromide (CTAB) template in basic media to form a steam stable hexagonal MCM-41 analog. It was later extended for the synthesis of different mesostructures including hexagonal (MSU-S, MSU-S/H, MAS, SAZ), cubic (MCM-48), wormhole (HMS, MSU-X), and foam-like (MCF, MSU-F) structures from different zeolite seeds such as Y, ZSM-5, Beta etc. under a variety of assembly conditions [13-15]. The resulting materials in most cases show ordered mesostructures with retained zeolite building units in the mesopore walls which are thought to be responsible for their improved hydrothermal stability and acidic properties. As a result, they exhibit higher catalytic activities in the 
conversion of large molecules, e.g., 1,3,5-tri-isopropylbenzene (TIPB) compared to OMMs and zeolites. Unfortunately, they display lower conversions of smaller molecules, e.g., cumene, which are mainly cracked in the presence of strong Brønsted acid sites of zeolites. The reason is that the preserved zeolite building units in the mesoporous walls cannot exceed the range of a few unit cells because of the small size of preformed zeolite precursors required for the self-assembly of a mesostructured matrix [31,32]. In fact, these composite materials were still $\mathrm{X}$-ray amorphous at high angles and contained a negligible fraction of micropores.

To improve the acidic properties of MZCs prepared from zeolite precursors, various modifications of the synthesis procedure have been explored in recent years. One promising route is to utilize zeolite precursors containing intact zeolite crystals for the self-assembly of mesostructures. Herein, the unreacted precursors, which have not been consumed in the evolution of zeolite crystals in the first step, can assemble into a mesostructure in the second step by $\mathrm{pH}$ adjusting prior to hydrothermal treatment [33-40]. The obtained MZCs such as ZSM-5/MCM-48 [33], L/MCM-41 [35], Beta/FDU-12 [36], Beta/SBA-15 [37] etc. comprise a zeolite phase intermixed with a mesophase, and the distribution of which can be tuned synthetically by the precrystallization conditions, i.e., initial $\mathrm{Si} / \mathrm{Al}$ ratios, precrystallization time and temperature. The acidic properties of these resulting composites are substantially enhanced because of the presence of the zeolite phase. However, it is noteworthy to mention that most of these syntheses were carried out at mild temperatures in the second step (typically $100-150{ }^{\circ} \mathrm{C}$ ) to avoid the decomposition of surfactant templates. This results in an imperfectly condensed mesoporous phase and thereby unsatisfactory hydrothermal stability. In this respect, we have recently developed a synthesis procedure for enhanced hydrothermal stability of MZCs composites by employing high-temperature hydrothermal treatment in mildly acidic media in the second step [41]. It was successfully applied for the synthesis of nano-ZSM-5/SBA-15 analog composites. The resulting material, denoted as ZSC, shows nano-ZSM- 5 crystals embedded in highly condensed mesoporous SBA-15 analogs and the content of both phases can be roughly controlled by the precrystallization time (Figure 3). The micro/mesoporous structure of ZSC composites is well maintained even after steaming at $800{ }^{\circ} \mathrm{C}$ for $24 \mathrm{~h}$ while their acidic properties and pore accessibility are considerably improved as proved by gas phase cracking of cumene and TIPB as model compounds (Figure 4).
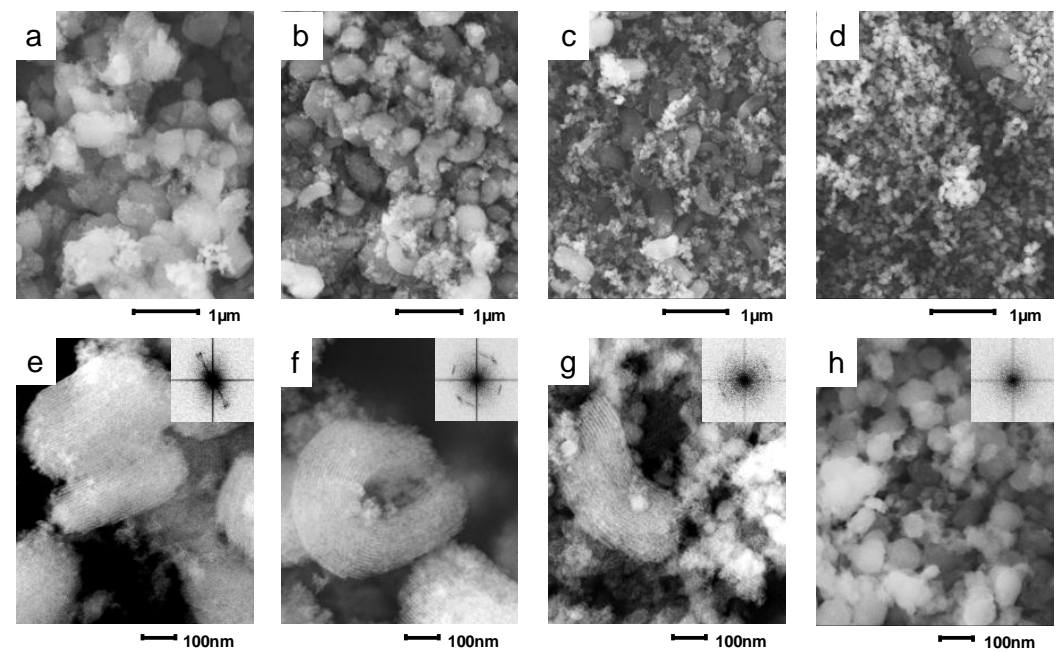

Figure 3. Scanning electron microscopy (SEM) images of nano ZSM-5/SBA-15 analog (ZSC) composites with various precrystallization times of either $6,12,24$ or $36 \mathrm{~h}$ (from left to right): (a-d) SEM images with $20 \times$ magnification shown in upper row; (e-h) $100 \times$ images in lower row; (e,f,g) Insets show FFT (Fast Fourier Transformation) images of the respective SEM to illustrate presence or (h) absence of periodically ordered mesoporosity [41]. This figure was published in J. Mater. Sci., Direct synthesis of nanosized-ZSM-5/SBA-15 analog composites from preformed ZSM-5 precursors for improved catalytic performance as cracking catalyst, 49, 2014, 5676-5689, Vu, X.H.; Bentrup, U.; Hunger, M.; Kraehnert, R.; Armbruster, U.; Martin, A. Reproduced with permission of Springer. 

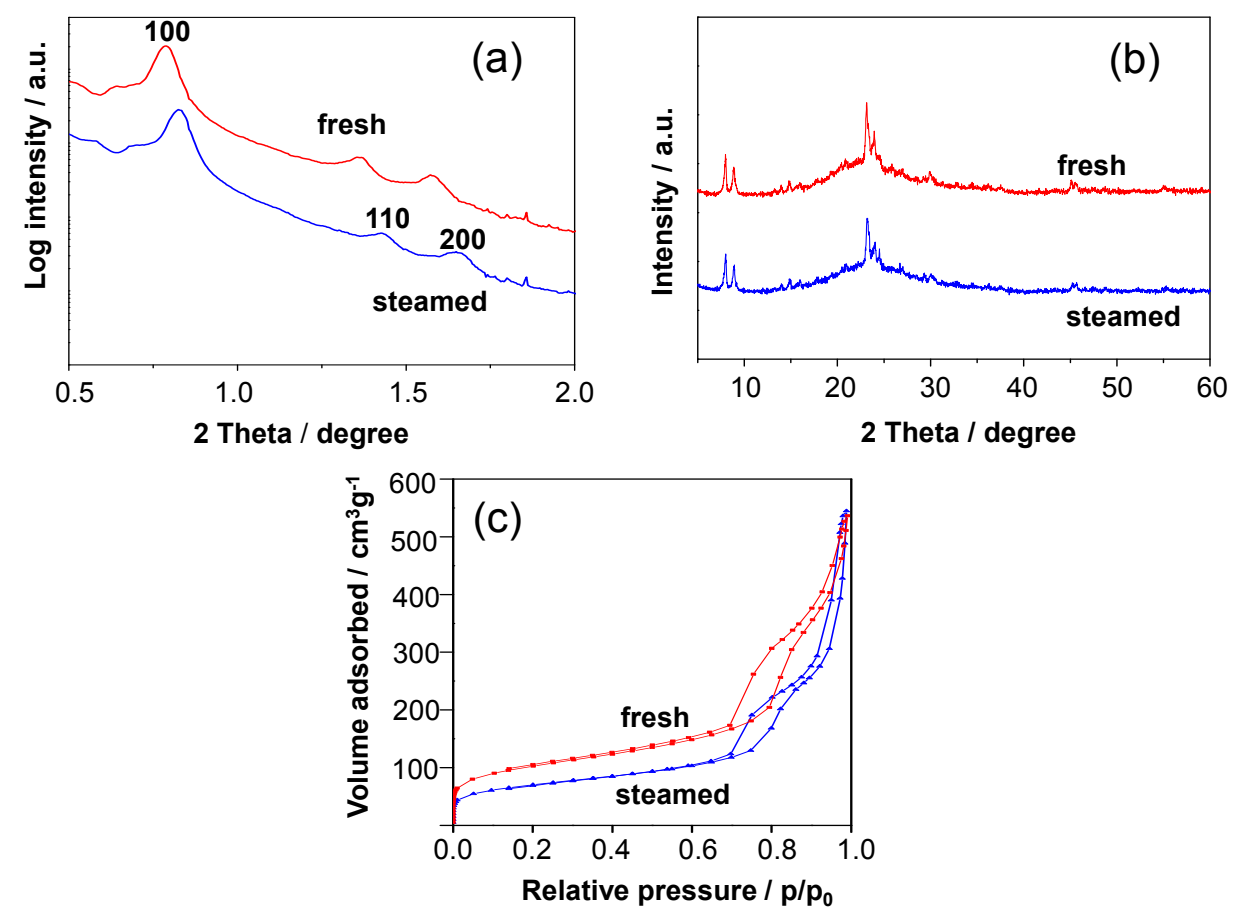

Figure 4. Effect of steaming of the ZSC composite at $800{ }^{\circ} \mathrm{C}$ for $24 \mathrm{~h}$ on the structural and textural properties: (a) Small-angle X-ray scattering (SAXS), (b) X-ray diffraction (XRD) and (c) $\mathrm{N}_{2}$ sorption isotherms [41]. This figure was published in J. Mater. Sci., Direct synthesis of nanosized-ZSM-5/SBA-15 analog composites from preformed ZSM- 5 precursors for improved catalytic performance as cracking catalyst, 49, 2014, 5676-5689, Vu, X.H.; Bentrup, U.; Hunger, M.; Kraehnert, R.; Armbruster, U.; Martin, A. Reproduced with permission of Springer.

An alternative route is to add well-defined zeolite crystals to the synthesis mixture of the mesoporous material which provides more precise control of zeolite phase and mesoporous phase distribution [31,42-49]. By this way, a variety of composites such as Beta/TUD-1 [31], MCM-22/MCM-41 [42], Silicalite-1@SBA-15 [43], Y/MCM-48 [47] have been synthesized under different synthesis conditions. The resulting materials in many cases show core-shell structured composites by overgrowth of the mesophase on the surface of pre-added zeolite crystals. Excellent examples are the core-shell structured zeolite@SBA-15 composites with controllable shell thickness developed by Qian et al. [43] by addition of zeolite crystals, i.e., Silicalite-1 or ZSM-5, to an ultra-dilute synthesis mixture of SBA-15. The micro/mesoporous core-shell structure consists of zeolite cores directly connected with the large mesopores of SBA-15 shells, forming a highly opened junction between microporous and mesoporous frameworks (Figure 5). 

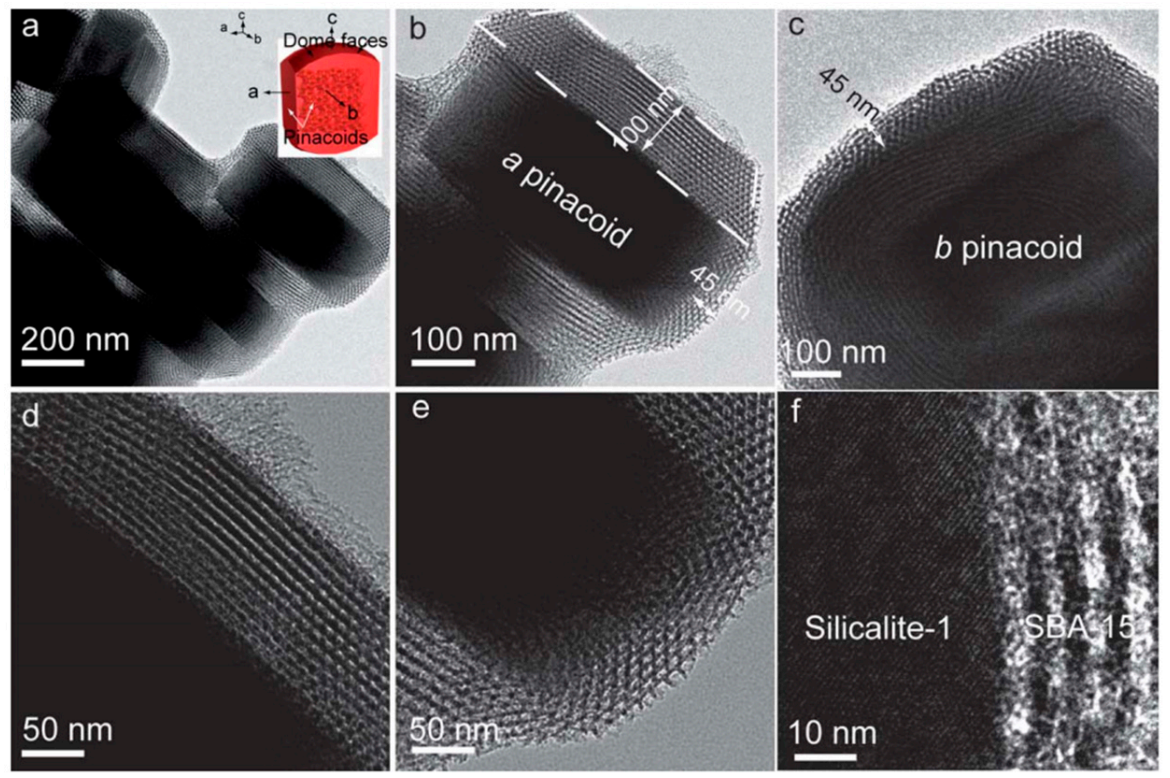

Figure 5. Transmission electron microscopy (TEM) images of a core-shell structured composite Silicalite-1@SBA-15 with a well-defined mesostructured shell: (a) Uniform core-shell particles without separated SBA-15; (b) a core-shell particle with shell thickness of ca.100 nm on $b$ pinacoid and of ca. $45 \mathrm{~nm}$ on dome face; (c) a core-shell particle with shell thickness of ca.45 nm on $a$ pinacoid; (d) strip-like mesopores and (e) hexagonal mesopores closely connected with Silicalite-1; (f) cross-section High-Resolution Transmission Electron Microscopy (HRTEM) image of the core-shell composite revealing the highly interconnected micropores and mesopores. Inset in (a) is the geometric model of a Silicalite-1 single-crystal. Reproduced with permission from [43]. Copyright Royal Society of Chemistry, 2011.

\subsection{Recrystallization of Zeolite Crystals}

Recrystallization of zeolite crystals has been shown to be a versatile and effective route for preparation of MZCs with superior catalytic properties. In a first step, zeolite crystals are submitted to alkaline media for partial or complete dissolution. The subsequent step converts the dissolved zeolite species to mesostructures which are deposited back onto the zeolite crystal surface. Goto et al. [50] first realized this concept in 2002 by partial dissolution of ZSM- 5 and mordenite zeolites in alkaline media $(0.75-3 \mathrm{M} \mathrm{NaOH})$ followed by reassembly of these species into a mesostructure by hydrothermal treatment in the presence of hexadecyltrimetylammonium chloride (HDTMACl) as the mesostructural template. The obtained solids, denoted as ZMC, comprise zeolite crystals embedded in the mesoporous matrix which results in close contact between the microphase and mesophase. The ZMC composites possess strong acidity comparable to their parent zeolites. Furthermore, the cracking activity of ZMC is higher than that of parent ZSM-5 in the cracking of n-hexane, which is attributable to the improved molecular transport provided by the bimodal pore system of ZMC catalysts. Inspired by these findings, a large number of studies have been reported on the recrystallization of zeolite crystals to create MZC materials [28,51-72]. Various zeolites such as ZSM-5, beta, mordenite, Y, MCM-22 etc. have been submitted to alkaline treatment and subsequent self-assembly, in most cases in the presence of long-chain alkylammonium surfactants such as CTAB. The alkaline treatment was later found to generate intracrystalline mesopores in zeolite crystals along with dissolved zeolite fragments as building blocks for self-assembly of mesostructured materials, mainly MCM-41 analogs.

The detailed mechanism has been recently proposed by Ivanova et al. $[58,67]$ who made intense efforts on the recrystallization of mordenite (Figure 6). At the first step of the process, zeolite desilication and ion exchange of protons with $\mathrm{Na}^{+}$proceed very fast which generate both intracrystalline and intercrystalline mesopores. The formation of negatively charged sites during desilication attracts 
cationic surfactants to diffuse into the intercrystalline space and the zeolite intracrystalline voids. This gives rise to micelle formation and therefore nucleation of the mesoporous phase inside the intracrystalline mesopores and on the external surface of the zeolite crystals. In the final step, the condensation of extracted species around the micelles under hydrothermal treatment results in the formation of core-shell structured composites consisting of zeolite crystals with ingrown and overgrown mesophase.

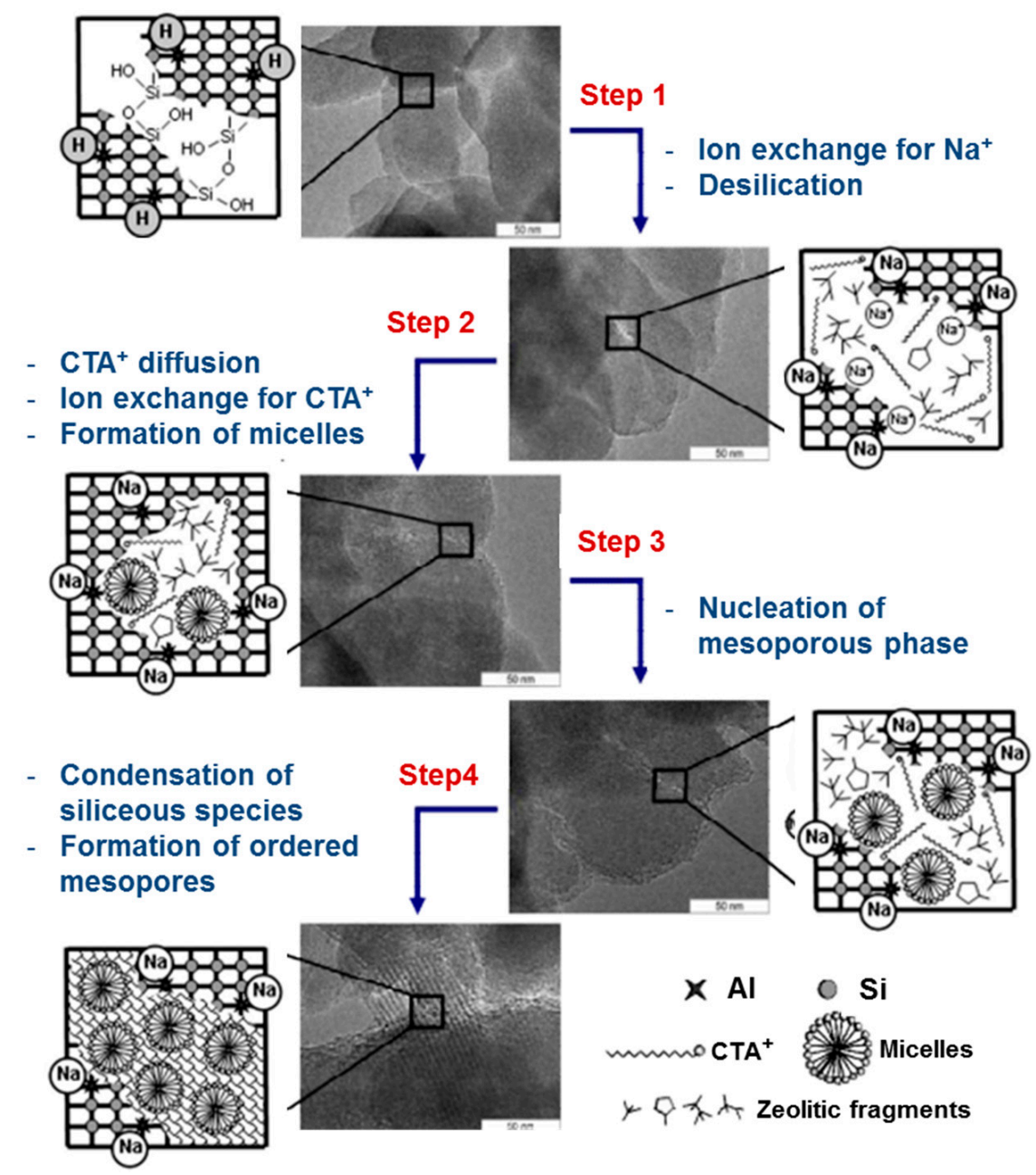

Figure 6. Schematic illustration of the major steps of mordenite recrystallization mechanism. Adapted with permission from [67]. Copyright Royal Society of Chemistry, 2014.

The relative amount of zeolite phase and mesoporous phase, thus ruling the physicochemical properties of the resulting composites, is mainly governed by the degree of recrystallization via alkaline treatment [28]. When the zeolite is treated in mild alkaline media, only small fractions of dissolved zeolite species are generated and the self-assembly of these species brings about a thin layer of mesoporous phase covering the treated zeolite crystals (Figure 7a,d). In contrast, complete dissolution of zeolite crystals by strong alkaline treatment leads to the formation of pure mesoporous materials with zeolite building units in the mesoporous walls (Figure $7 \mathrm{c}, \mathrm{f})$. In between, the composite materials comprise zeolite crystals with ingrown and overgrown mesophase, inducing core-shell structures with an interconnected bimodal pore system (Figure $7 \mathrm{~b}, \mathrm{e}$ ). 

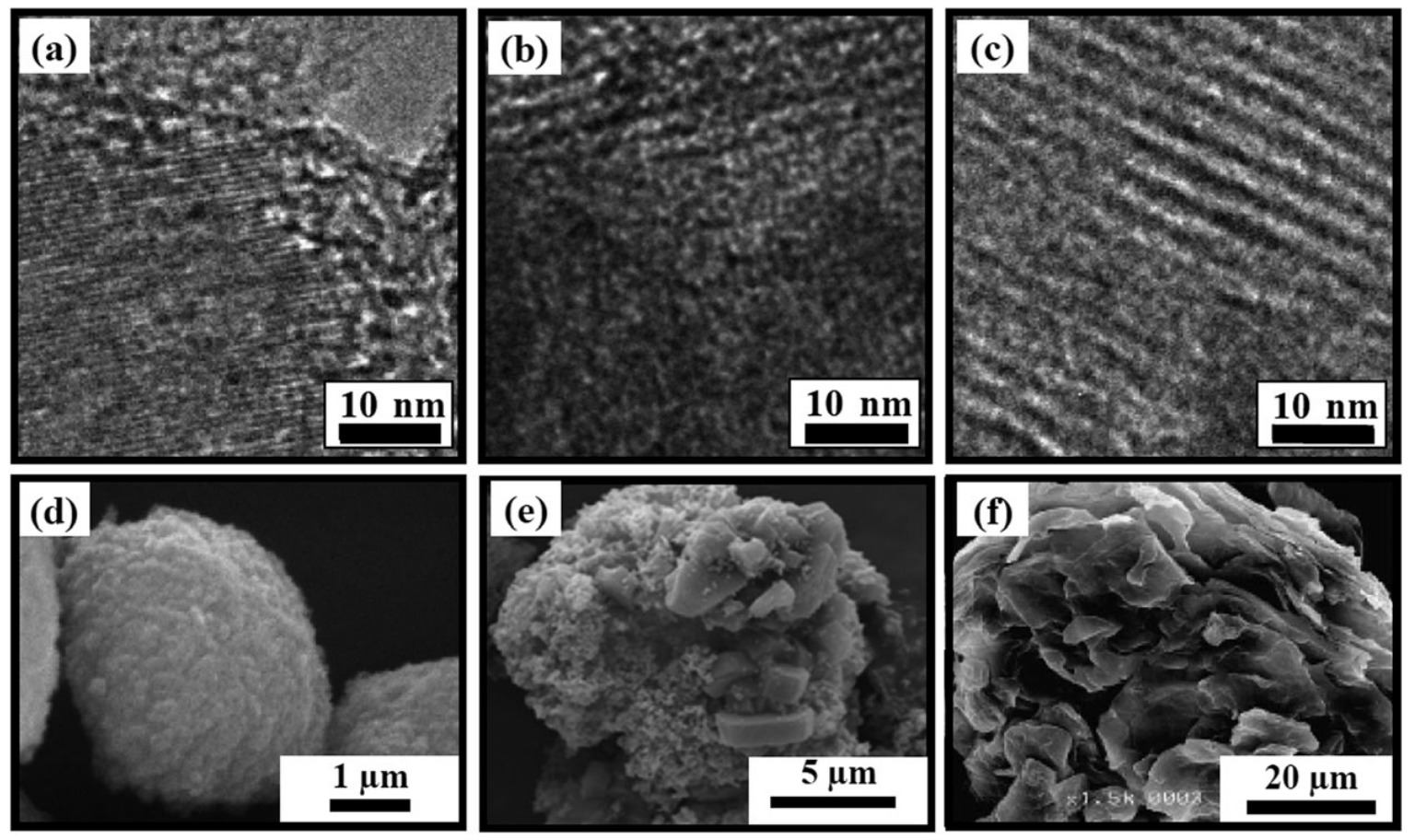

Figure 7. TEM images of mordenite/MCM-41 composites (a-c) and SEM images of MFI/MCM-41 composites $(\mathbf{d}-\mathbf{f})$ obtained at various degrees of recrystallization of mordenite and ZSM- 5 respectively. Reproduced with permission from [28]. Copyright Royal Society of Chemistry, 2013.

\subsection{Zeolitization of Preformed Mesoporous Materials}

In contrast to the recrystallization of zeolite crystals, this approach uses preformed mesoporous materials as starting materials for partial transformation into zeolite phase. Generally, this is a two-step process in which mesoporous materials are first prepared, followed by zeolitization of their amorphous mesoporous walls under zeolite synthesis conditions to obtain MZCs. The first attempt was reported by Kloetstra et al. [73] in 1997. The authors performed the recrystallization of mesoporous walls of MCM-41 and HMS by ion-exchanged tetrapropylammonium template and subsequent hydrothermal treatment in glycerol. The resulting materials, coded as PNA-1 and PNA-2 corresponding to the parent MCM-41 and HMS respectively, exhibit disordered mesoporous materials with embryonal ZSM-5 in the mesoporous walls. Later, Verhoef et al. [74] demonstrated the formation of small particles containing ZSM-5 structure of approximately $3 \mathrm{~nm}$ during the partial transformation of mesoporous walls of MCM-41 under hydrothermal treatment. Attempts to create well-defined ZSM- 5 nanocrystals by partial recrystallization of MCM-41 type materials often lead to the collapse of the MCM-41 framework and the formation of segregated zeolite crystals [75,76]. The main reason is that mesoporous walls of MCM-41 type materials are too thin (less than $2 \mathrm{~nm}$ ) to accommodate the highly developed zeolitic nanoparticles. In this connection, SBA-15 type materials with walls thicker than $3 \mathrm{~nm}$ would be better suited as starting materials. However, the hydrothermal treatment of SBA-15 type materials still induced the formation of segregated zeolite crystals at the expense of mesoporous walls (Figure 8). 


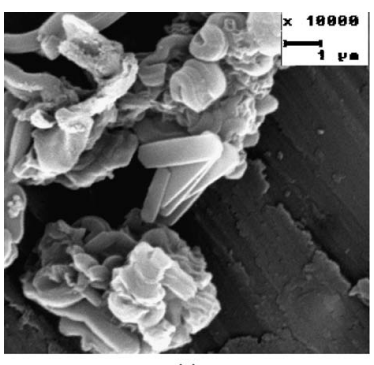

(a)

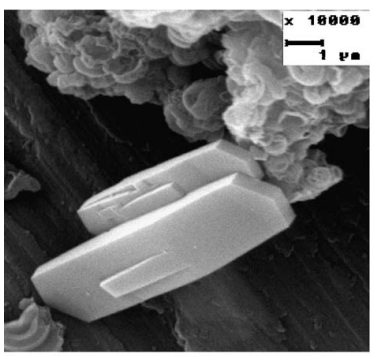

(c)

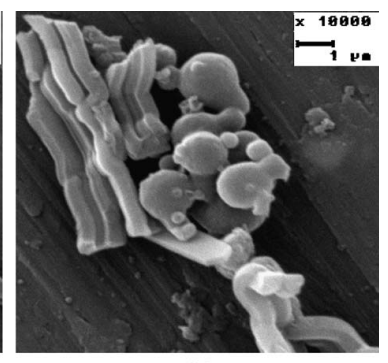

(b)

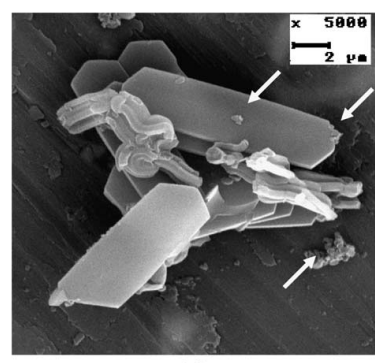

(d)

Figure 8. SEM images of zeolitization of SBA-15 into ZSM- 5 for different crystallization time: (a) $24 \mathrm{~h}$, (b) $48 \mathrm{~h}$, (c) $60 \mathrm{~h}$, and (d) $72 \mathrm{~h}$. The white arrows show the segregated ZSM-5 crystals [77]. This figure was published in Microporous Mesoporous Mater., Vol. 95, Campos, A.A.; Dimitrov, L.; da Silva, C.R.; Wallau, M.; Urquieta-González, E.A., Recrystallisation of mesoporous SBA-15 into microporous ZSM-5, 92-103, Copyright Elsevier (2006).

To avoid the phase separation and the destruction of mesoporous walls during the zeolite crystallization, the steam assisted crystallization (SAC) method was employed [78-84]. In this process, parent mesoporous materials in the form of dried gel precursors are brought into contact only with water vapor and/or additional microporous template molecules are transported to the mesoporous material by steam. Thus, the mass transfer during the crystallization process was substantially suppressed due to the absence of a liquid phase. This greatly contributes to the preservation of mesoporous walls during the SAC process. Based on this method, various composite materials such UL-ZSM-5 [78], TUD [79,80], MCM-22/SBA-15 [82] etc. have been successfully developed. The resulting composites display nanosized zeolite crystals embedded in the interconnected mesoporous matrix, forming semicrystalline walls while retaining the mesoporous structure. The distribution of zeolite crystals and mesoporous phase can be adjusted by varying the crystallization conditions. It has been reported that the pore wall thickness, the slow conversion into zeolitic crystalline aluminosilicate, as well as mesostructured supports such as carbon inside the mesopores are favorable for the preservation of the mesostructure during the SAC process (Figure 9) [78-82].

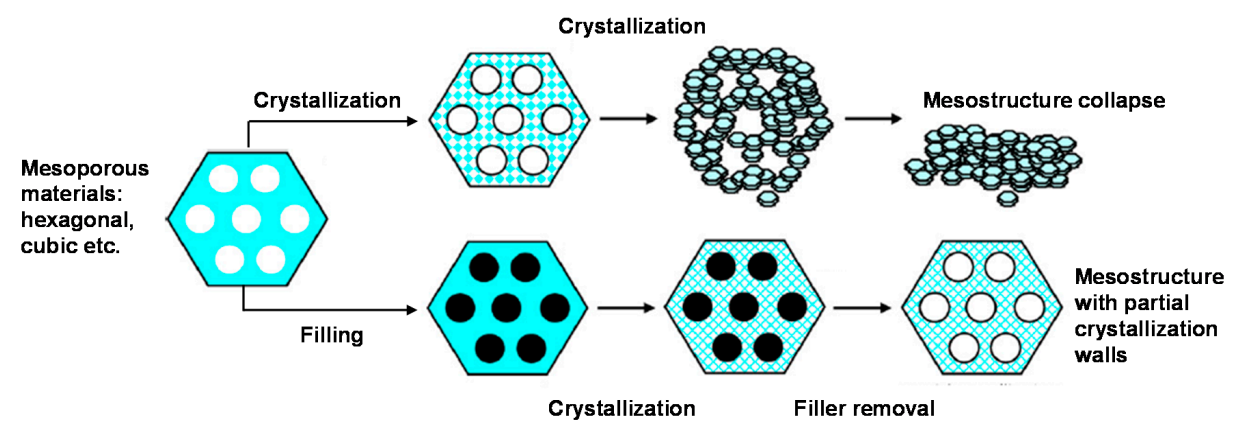

Figure 9. Schematic representation of the strategy for retaining the mesostructure of parent mesoporous materials in the steam assisted crystallization (SAC) process for preparation of MZCs [82]. Parts of this figure were published in Catal. Today, Vol. 168, Ogura, M.; Inoue, K.; Yamaguchi, T., A mechanistic study on the synthesis of MCM-22 from SBA-15 by dry gel conversion to form a micro- and mesoporous composite, pp. 118-123, Copyright Elsevier (2011). 


\section{Catalytic Applications of Micro/Mesoporous Zeolitic Composites}

Catalytic applications of MZCs have been extensively investigated in recent years. The superior catalytic performance of MZC catalysts compared to conventional zeolites, OMMs and mechanical mixtures thereof has been demonstrated in both traditional and emerging catalytic applications of industrial relevance such as catalytic cracking, alkylation, methanol-to-hydrocarbons reactions, and hydroconversions. In this section, we highlight some typical examples that have been recently published on the catalytic applications of MZC materials.

\subsection{Catalytic Cracking}

Zeolites, particularly Y and ZSM-5 are widely used as industrial cracking catalysts. Despite the great success of zeolites in the application for fluid catalytic cracking (FCC), the diffusion limitations have been recognized as a major problem that needs to be solved, especially when processing low quality feedstocks such as heavy oils or biogenic resources. In this area, MZC materials not only help to alleviate the diffusion limitations and to increase the accessibility of acid sites but also help to pre-crack bulky molecules into intermediates that could then enter the pores of zeolites and react on strong acid sites $[13,14,31,39,41,50,54,62,64,85-90]$.

$\mathrm{Vu}$ et al. [41] showed that greatly improved pore accessibility can be achieved over nano-ZSM-5/SBA-5 analog composite (denoted as ZSC-24) prepared by dispersion of nano-ZSM-5 in highly condensed mesoporous SBA-15 analogs via the direct synthesis route. This was clearly proved in the gas phase cracking of cumene and TIPB as model compounds. In relation to commercial ZSM-5 which shows the highest conversion of cumene (ca. 94\%), the ZSC-24 catalyst displays comparable conversion (ca. 80\%) despite its much lower density of acid sites. On the other hand, ZSC-24 shows a much higher conversion of cumene than Al-SBA-15 (ca. 13\%) with a similar Si/Al ratio of 30 . For the cracking of TIPB, the ZSC-24 catalyst reveals a TIPB conversion of ca. $80 \%$ being as high as that of Al-SBA-15 (ca. 85\%) while commercial ZSM-5 reaches only about $62 \%$. Furthermore, the performance of the ZSC-24 composite with respect to commercial ZSM- 5 and Al-SBA-15 has been evaluated in the cracking of biogenic feedstock, i.e., waste cooking oil under FCC conditions [85]. It was found that the ZSC-24 catalysts are superior, producing the remarkably higher selectivity toward $\mathrm{C}_{2}-\mathrm{C}_{4}$ olefins than commercial ZSM-5 and Al-SBA-15 (Table 1). The improved molecular transport provided by the mesopores of SBA- 15 analogs and the shorter diffusion path length inside nano-ZSM- 5 coupled to medium acidity is likely to be responsible for the superior catalytic performance of the ZSC catalyst.

Table 1. Hydrocarbon gas compositions obtained in the catalytic cracking of waste cooking oil over ZSC-24 material relative to HZSM-5 and Al-SBA-15 catalysts. Adapted from [85].

\begin{tabular}{cccc}
\hline Compound & ZSC-24 & HZSM-5 & Al-SBA-15 \\
\hline Methane & 1.7 & 0.9 & 5.1 \\
Ethane & 2.3 & 1.7 & 6.0 \\
Ethene & 6.5 & 16.9 & 9.0 \\
Propane & 2.4 & 14.2 & 5.3 \\
Propene & 41.9 & 32.9 & 30.4 \\
i-Butane & 0.6 & 4.8 & 0.5 \\
n-Butane & 1.5 & 5.6 & 4.1 \\
t-2-Butene & 10.9 & 5.6 & 11.0 \\
1-Butene & 8.7 & 4.4 & 8.9 \\
i-Butene & 15.9 & 8.9 & 11.6 \\
c-2-Butene & 7.9 & 4.1 & 8.2 \\
Selectivity to C $_{2}-C_{4}$ olefins $(\%)^{\text {a }}$ & 93.2 & 73.5 & 83.3 \\
\hline
\end{tabular}

${ }^{\mathrm{a}}$ fraction of $\mathrm{C}_{2}-\mathrm{C}_{4}$ olefins per total $\mathrm{C}_{2}-\mathrm{C}_{4}$ hydrocarbons. 
Diao et al. [62] developed core-shell structured composites by the treatment of HZSM-5 with tetramethyl- and tetraethyl-ammonium hydroxide (TMAOH and $\mathrm{TEAOH}$, respectively) and subsequent recrystallization with CTAB. The resulting core-shell meso-HZSM-5@Al-MCM-41 composites exhibit the meso-HZSM- 5 core overgrown by Al-MCM-41 shell with thicknesses of $58 \mathrm{~nm}$ and $27 \mathrm{~nm}$, respectively. Catalytic cracking of supercritical n-dodecane $\left(500{ }^{\circ} \mathrm{C}, 4 \mathrm{MPa}\right)$ over the zeolite composites revealed that the pre-cracking of $n$-dodecane over the Al-MCM-41 shell and the enhanced diffusion in the meso-HZSM-5 core led to excellent catalytic performance of the meso-HZSM-5@Al-MCM-41 with an improvement in catalytic activity up to 31\% and the lowest deactivation rate (only one fourth) compared with the parent HZSM-5 (Figure 10).

(a)

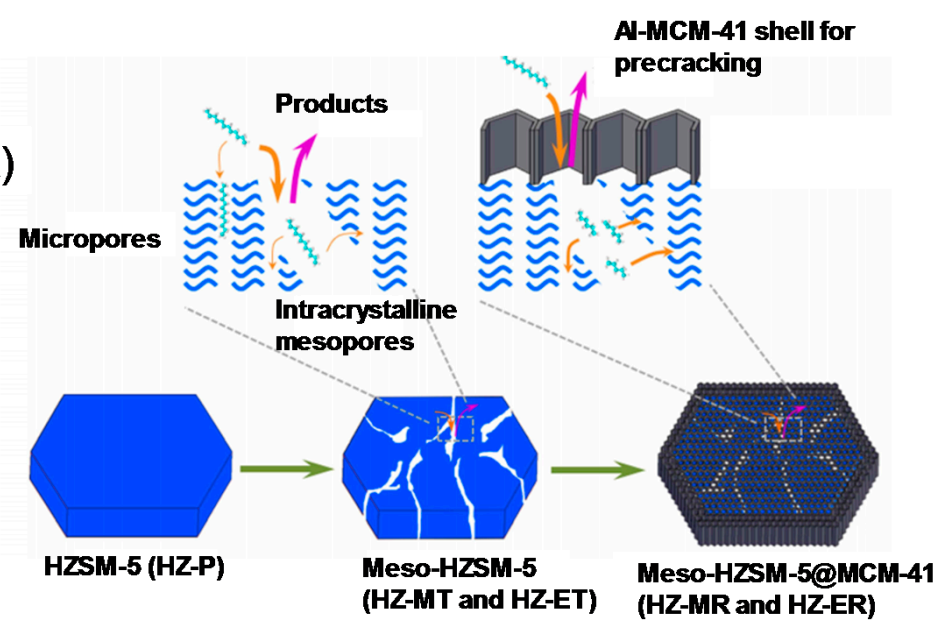

(b)

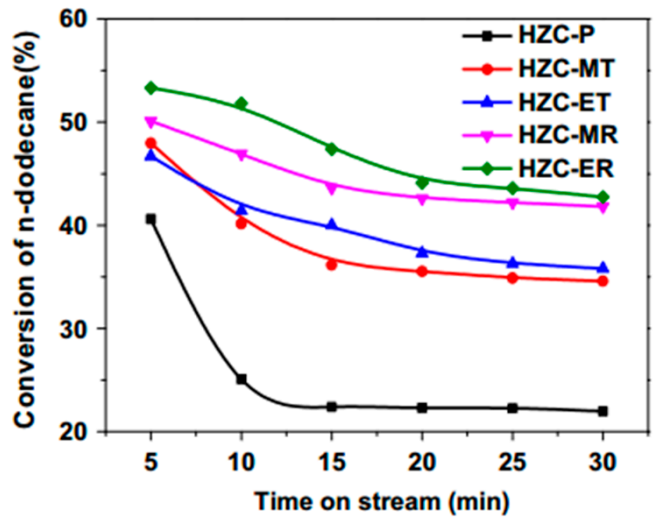

Figure 10. Desilication of the HZSM-5 (HZ-P) with tetramethyl-ammonium hydroxide (TMAOH) and tetraethyl-ammonium hydroxide (TEAOH) (denoted as HZ-MT and HZ-ET respectively) and subsequent recrystallization (denoted as HZ-MR and HZ-ER respectively): (a) Schematic illustration of the catalytic cracking of $n$-dodecane over HZs and (b) Conversion of n-dodecane over HZCs catalysts prepared by deposition of HZs onto the inner surface of the stainless steel tubular reactor. Adapted with permission from [7]. Copyright Royal Society of Chemistry, 2015.

Similar observations were reported by Liu et al. [54] who carried out the cracking of vacuum gas oil (VGO) over Y/MCM-41 composite under FCC conditions. The core-shell structured Y/MCM-41 composites were prepared by recrystallization of zeolite $\mathrm{NaY}$ using alkaline treatment. It was found that the mesopores of the shell can promote the pre-cracking of bulky molecules and then increase the conversion of heavy oil. As a result, the $\mathrm{Y} / \mathrm{MCM}$ - 41 composite of well-organized core-shell structure produces a higher conversion of VGO and total liquid products than zeolite $\mathrm{Y}$ and the $\mathrm{Y} / \mathrm{MCM}-41$ with randomly orientated stacks. 


\subsection{Alkylation of Aromatics}

Zeolites are important industrial catalysts for benzene alkylation to produce important monomers for the petrochemical industry. MZC catalysts offer an enhanced efficiency compared to zeolite catalysts by lowering the diffusion limitation of the reactant and product, respectively, while retaining the shape-selectivity linked to the intrinsic microporosity of the zeolite $[28,45,51,52,91-93]$. Ivanova et al. $[28,51,52]$ studied the alkylation of benzene with dodec-1-ene and naphthalene with cyclohexene over MOR/MCM-41 composite catalysts (denoted as RMOR) obtained by recrystallization of mordenite (MOR) with CTAB. In the former reaction (Figure 11a), the increase in the reactant conversion and selectivity to the desired products, i.e., dodecylbenzenes, is obtained by the mild recrystallization of mordenite (RMOR-1). This is assigned to the shorter diffusion path length and enhanced accessibility of acid sites provided by the intracrystalline mesopores of RMOR-1. Moreover, the comparable high selectivity to linear dodecylbenzenes (84\%) of RMOR-1 and parent MOR evidences the preservation of shape-selectivity of the parent MOR. Increasing the degree of recrystallization (RMOR-2, RMOR-3) lowers the alkylation activity because of the significant reduction of acidity. Similar observations are found in the latter reaction with bulkier molecules (Figure 11b). Mild recrystallization of parent MOR (RMOR-1, RMOR-2) enhances the conversion of both naphthalene and cyclohexene and the selectivity toward the target product, i.e., cyclohexylnaphthalenes (CHN). However, severe treatment of MOR (RMOR-3) reduces the yield of CHN due to the secondary transformation of CHN to dicyclohexylnaphthalenes (DCHN).

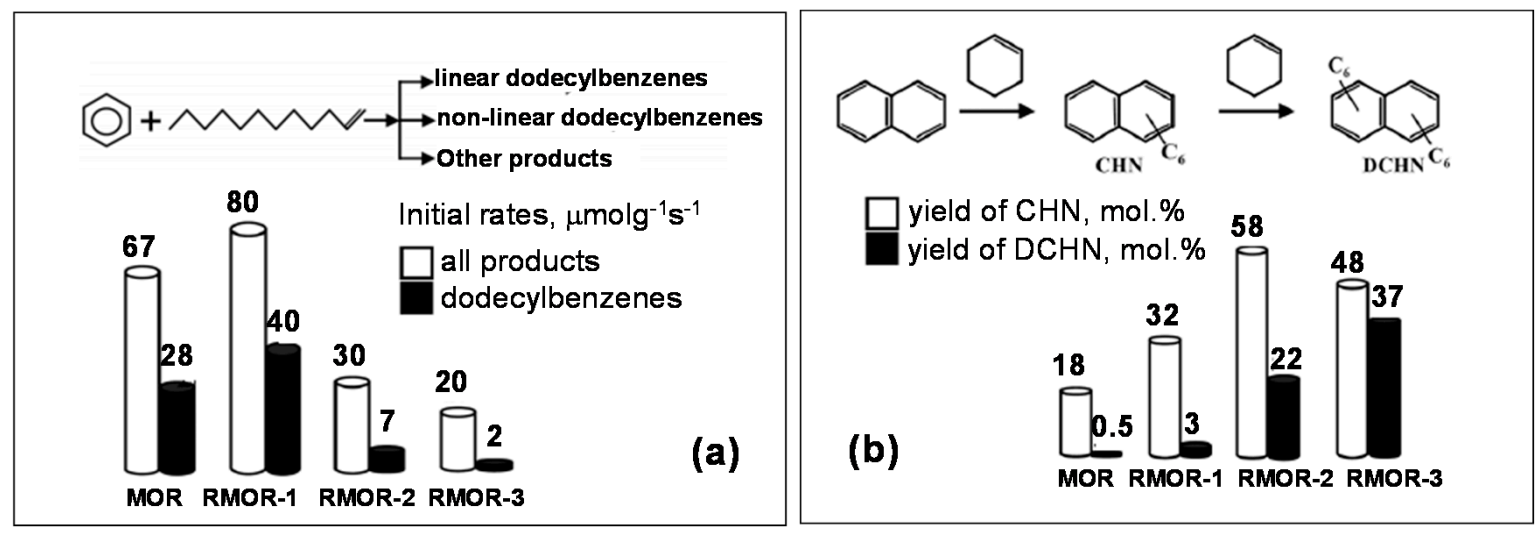

Figure 11. Catalytic performance of parent mordenite (MOR) and recrystallized MOR/MCM-41 composites (RMOR) in (a) alkylation of benzene with dodec-1-ene and (b) alkylation of naphthalene with cyclohexene. Adapted with permission from [28]. Copyright Royal Society of Chemistry, 2013.

Very recently, Lee et al. [92] reported remarkably improved catalytic performance of recrystallized MOR (Recry-MOR) in the alkylation of naphthalene with isopropyl alcohol for the production of 2,6-naphthalenedicarboxylate, the monomer of polyethylene naphthalate (PEN) plastic. The desired product is 2,6-diisopropylnaphthalene (DIPN) and the ultimate goal of the catalyst development for this process is to achieve high activity and high 2,6-DIPN/2,7-DIPN ratio. By mild recrystallization of MOR with $\mathrm{CTAB}$, the resulting composite shows much higher conversions of naphthalene as well as catalytic stability (Figure 12a). This indicates that the formation of an inter-connected micro/mesoporous system in the Recry-MOR catalyst facilitated the facial diffusion of bulky molecules to and from active catalytic sites located in the pores of MOR, thereby allowing the higher conversion of naphthalene. Moreover, a comparable 2,6-DIPN/2,7-DIPN ratio between the parent MOR and Recry-MOR confirms that the intrinsic high shape-selectivity of MOR for 2,6-diisopropylnaphthalene is maintained (Figure 12b). 

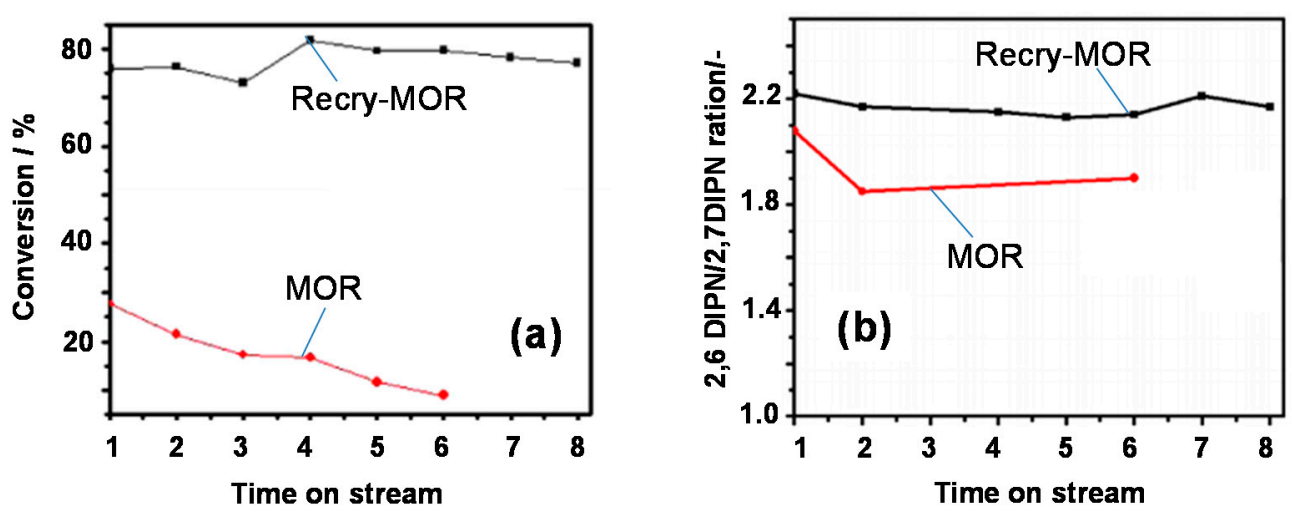

Figure 12. Catalytic performance of parent mordenite (MOR) and recrystallized MOR/MCM-41 composites (Recry-MOR) in the alkylation of naphthalene with isopropyl alcohol: (a) conversion of naphthalene and (b) 2,6-diisopropylnaphthalene (DIPN)/2,7-DIPN ratio with time-on-stream [92]. Lee, Y.H.; Kim, W.Y.; Park, H.; Choi, Y.H.; Lee, J.S. Highly active and coke-tolerant hierarchical mordenite catalysts synthesized by recrystallization for the isopropylation of naphthalene. ChemCatChem 2016, 8, 2996-3001. Copyright Wiley-VCH Verlag GmbH \& Co. KGaA. Reproduced with permission.

Another advantage of MZC catalysts in alkylation was reported by Xue et al. [42]. The authors developed H-MCM-22/MCM-41 composites by overgrowing of MCM-41 over the external surface of H-MCM-22 via direct synthesis and tested the resulting catalysts in alkylation of toluene with dimethyl carbonate to p-xylene. Interestingly, by decreasing the H-MCM-22/MCM-41 weight ratio from 7:1 to $1: 1$, the selectivity for p-xylene increases substantially while the conversion of toluene is maintained. This is attributed to the formation of a MCM-41 layer covering the Brønsted acid sites on the external surface of H-MCM-22. Hence, the nonselective alkylation on the external acid sites of the zeolite is effectively inhibited.

\subsection{Methanol-to-Hydrocarbons}

Methanol-to-hydrocarbons (MTH) reactions have emerged as an attractive alternative to produce a wide range of hydrocarbons such as gasoline and light olefins. Methanol can be produced from coal, natural gas or biomass. The conversion of methanol to gasoline range hydrocarbons (via the MTG process) was originally discovered by Mobil Oil using ZSM- 5 zeolite. However, the ZSM- 5 catalyst often produces gasoline with a high content of aromatics which is not desired from the environmental point of view. In this respect, Di et al. [38] developed a novel ZSM-5/MCM-48 composite by direct synthesis to reduce the formation of aromatics in the MTG reaction. The obtained composite consists of the ZSM-5 phase interconnected with the mesoporous MCM-48 phase, giving high activity and stability in the MTG reaction. In particular, the content of aromatics in the liquid fraction ranges from 35 to $46 \mathrm{wt} \%$, which is significantly lower than that (ca. 65-84 wt \%) observed with commercial HZSM- 5 catalysts. The catalytic superiority is attributable to the reduced diffusion limitations caused by the widened pore size distribution and lowered pore surface acidity of the composite catalyst.

Similar effects of acidity and porosity were also reported in the conversion of methanol to lower olefins (via MTO process) over a core-shell composite catalyst (Figure 13). Qian et al. [43] evaluated the catalytic performance of such a composite containing $70 \mathrm{wt} \% \mathrm{HZSM}-5$ core and $30 \mathrm{wt} \%$ mesoporous SBA-15 shell (HZ@S15) relative to pristine HZSM-5 (100 wt \%) and a mechanical mixture containing 70 wt $\%$ of HZSM- 5 and 30 wt \% of SBA-15 (HZSM-5\&S15) in the MTO reaction. It was found that HZ@S15 catalysts display excellent catalytic performance with high conversion (98\%) and high selectivity to propene $(39 \%)$. Especially, the propene to ethene $(\mathrm{P} / \mathrm{E})$ ratio for the core-shell catalyst is higher than that of pristine HZSM-5. The mesoporous silica shell with large surface area and pore channels facilitates molecular diffusion, enhancing the accessibility of acid sites of ZSM-5. This leads 
to high methanol conversion and propene selectivity even though the content of active HZSM-5 (70 wt \%) is less than in pristine HZSM-5. Furthermore, the mesoporous shell also partially covers the surface acidity of the zeolite, reducing the selectivity to ethene and thus establishing a higher $\mathrm{P} / \mathrm{E}$ ratio over the core-shell composite with respect to pristine HZSM-5. Compared to the mechanical mixture HZSM-5\&S15, the core-shell catalyst exhibits an obvious enhancement in catalytic activity which further stresses the importance of the interconnected micro/mesoporous system in catalysis.
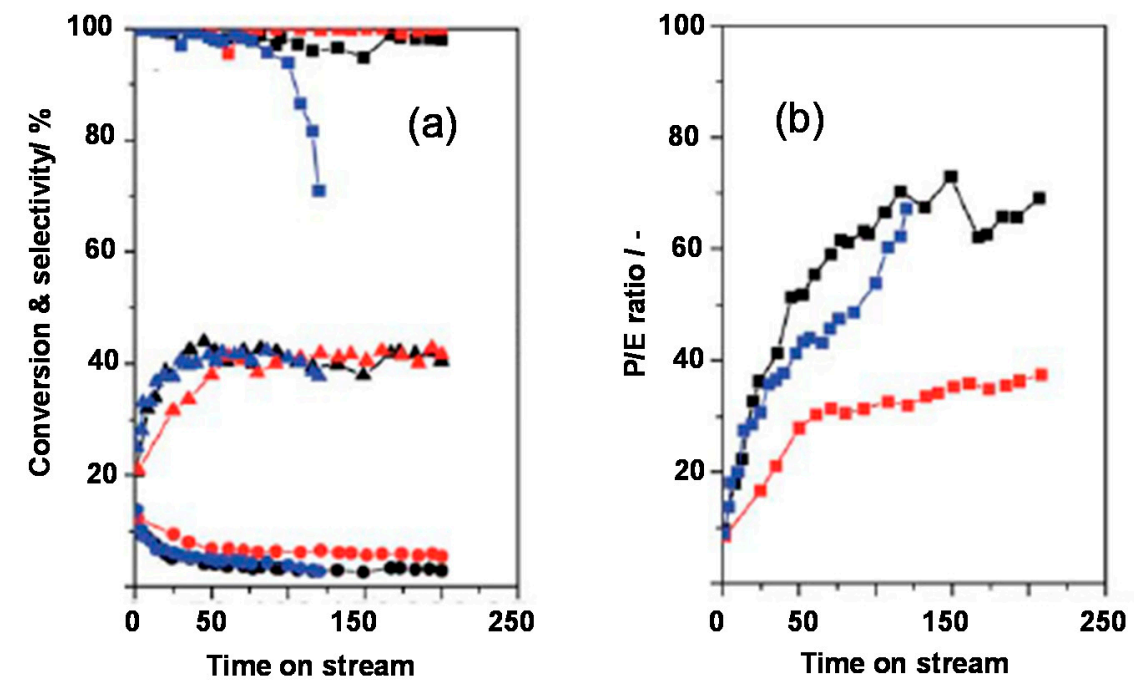

Figure 13. The catalytic performance of pristine HZSM-5 (red color), the mechanical mixture HZSM-5@S15 (blue color) and HZ@15 composite (black color): (a) methanol conversion (square), selectivity of ethylene (circle) and propylene (triangle); (b) the propylene to ethylene (P/E) ratio. Adapted with permission from [43]. Copyright Royal Society of Chemistry, 2011.

\subsection{Hydroconversion}

Unlike the previous catalytic reactions which are mainly catalyzed by acid catalysts, hydroconversion processes such as hydrodesulfurization, hydrocracking, and hydroisomerization require bifunctional catalysts containing acidic and metal sites. The balance of these functions plays a crucial role in the design of novel hydroconversion catalysts. In this context, MZC materials have recently gained extensive attention because they offer appropriate acidic properties, improved molecular transport capabilities, and high metal distribution with respect to conventional zeolites and OMMs.

Hydrodesulfurization (HDS) is currently one of the most widely used techniques in refineries to reduce the sulfur content in gasoline. However, it is generally accompanied by a decreased gasoline octane number due to olefin saturation in the hydrogenation process. Thus, the development of novel catalysts which not only show improved desulfurization but also preservation of the octane number is of crucial importance for hydro-upgrading technology. This has been realized by using MZC materials such as L/MCM-41 [35], Beta/SBA-15 [37], ZSM-5/KIT6 [94], and Beta/KIT6 [95] as advanced supports for the preparation of HDS catalysts. Especially, Du et al. [36] recently developed excellent HDS catalysts by using micro/mesoporous composite Beta/FDU-12 (BF) as a support additive mixed with $\gamma-\mathrm{Al}_{2} \mathrm{O}_{3}$ (BFA). The BF composites prepared by the direct synthesis route exhibit a Fm $3 \mathrm{~m}$ cubic ordered mesoporous structure similar to the pure silica material FDU-12 and its framework contains the microporous structure of Beta zeolite [36]. The combination use of $\mathrm{BF}$ and $\gamma-\mathrm{Al}_{2} \mathrm{O}_{3}$ as support catalysts yielded an appropriate distribution of Brønsted and Lewis acid sites with moderate acid strength; thus, a good balance among the HDS, hydroisomerization and aromatization reactions can be achieved. The large surface area and pore structure of BF enhance the dispersion and accessibility of active metal sites. The obtained catalyst CoMo/BFA displays a superior catalytic performance 
compared to the reference catalysts, e.g., $\mathrm{CoMo} / \gamma-\mathrm{Al}_{2} \mathrm{O}_{3}, \mathrm{CoMo} / \mathrm{FA}$, and CoMo/ZFA in the hydro-upgrading of full range FCC gasoline. Moreover, the authors emphasized that post-treatment with ethylenediaminetetraacetic acid (EDTA) improves the dispersion of the active metals, thus the resulting catalyst CoMoE/BFA shows the best hydro-upgrading performance for FCC gasoline (Figure 14).

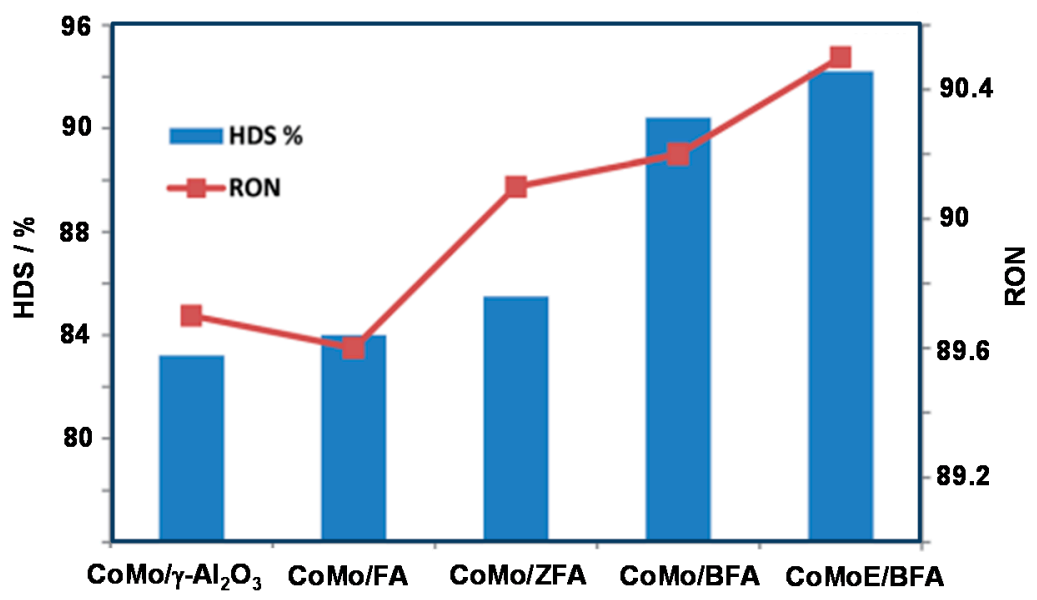

Figure 14. Catalytic performance of the $\mathrm{CoMo} / \mathrm{BFA}$ and $\mathrm{CoMoE} / \mathrm{BFA}$ catalysts in relation to the reference catalysts $\mathrm{CoMo} / \gamma-\mathrm{Al}_{2} \mathrm{O}_{3}, \mathrm{CoMo} / \mathrm{FA}$ and $\mathrm{CoMo} / \mathrm{ZFA}$ in the hydrodesulfurization (HDS) of full range fluid catalytic cracking (FCC) gasoline; FA-FDU-12 mixed with $\gamma-\mathrm{Al}_{2} \mathrm{O}_{3} ; \mathrm{ZFA}-\mathrm{Zr}$ incorporated FDU-12 mixed with $\gamma-\mathrm{Al}_{2} \mathrm{O}_{3}$, BFA-Beta/FDU-12 mixed with $\gamma-\mathrm{Al}_{2} \mathrm{O}_{3}$. Adapted with permission from [36]. Copyright Royal Society of Chemistry, 2016.

The effects of morphology on the physicochemical properties and consequent catalytic performance of MZCs in the FCC gasoline hydro-upgrading were reported by Gao et al. [37]. They synthesized Beta/SBA-15 (BS) composites with different morphologies including short-rods (BS-SR), long-rods (BS-LR), platelets (BS-PL), and spheres (BS-SP). Characterization results show that BS composites with different morphologies reveal Brønsted and Lewis acid sites with different strength and number as well as pore size induced by the different synthesis conditions. The platelet BS-PL exhibits short and large mesopores which facilitate molecular transport and increase the number of the brim active sites of $\mathrm{MoS}_{2}$ slabs. As a result, the HDS catalyst based on BS-PL gives the highest HDS conversion (97\%). The sphere BS-SP owns more mesopore cavities and appropriate acidity which are favorable for hydroisomerization and aromatization. Consequently, the HDS catalyst based on BS-SP yields superior research octane number (RON) preservation ability. In contrast, the short and long rod BS-LR and BS-SR solids display less mesoporosity and longer mesopores, leading to poor catalytic performance in the HDS reaction.

Another hydroconversion reaction which has been investigated over MZC based catalysts is hydrocracking, which contributes as an important process in the manufacture of middle distillates, e.g., diesel or jet fuels. The use of MZC materials for fabrication of hydrocracking catalysts induces an improved hydrocracking performance with high selectivity to target products [68,71,96-99]. Wang et al. [68] developed very promising hydrocracking catalysts based on core-shell-structured composites synthesized by recrystallization of ZSM- 5 crystals involving controlled desilication and subsequent Pluronic P-123 assisted self-assembly (Figure 15). The resulting composites, denoted as MZ@MSA consist of microporous/mesoporous ZSM-5 as core and mesoporous aluminosilicate as shell, resulting in a highly interconnected porous system from the exterior mesoporous shell to the inner micro/mesoporous core. The incorporation of Pt nanoparticles into the mesoporous shells induced a high dispersion of Pt nanoparticles with an average particle size of about $5 \mathrm{~nm}$. In contrast, the Pt nanoparticles supported on the bare ZSM- 5 crystals aggregated easily to form larger particles with less uniformity (Figure 16a). The catalytic performance of the Pt/MZ ${ }^{\circledR} \mathrm{MSA}$ composite 
with respect to conventional Pt/ZSM-5 was evaluated in the hydrocracking of n-hexadecane as a probe molecule. As expected, the bifunctional catalyst $\mathrm{Pt} / \mathrm{MZ}^{\circledR} \mathrm{MSA}$ revealed a higher conversion and a higher selectivity of $\mathrm{C}_{5}-\mathrm{C}_{11}$ liquid products compared to Pt/ZSM-5 catalyst (Figure 16b,c). The improvement is presumed to be the contribution of the hierarchical pore system of the composite which on the one hand enhances the accessibility of n-hexadecane to zeolite acid sites, thus leading to higher conversion and on the other hand inhibiting the over-cracking of the intermediate $\mathrm{C}_{5}-\mathrm{C}_{11}$ hydrocarbons by the shortened diffusion path length, finally allowing higher selectivity to middle distillates.

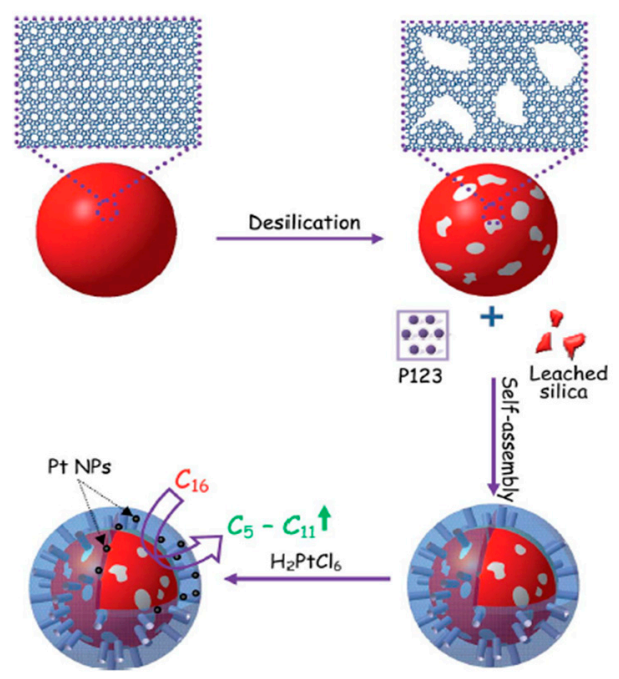

Figure 15. Schematic illustration of the synthesis of a novel HDS catalyst with PtMZ@MSA. Reproduced with permission from [68]. Copyright Royal Society of Chemistry, 2014.
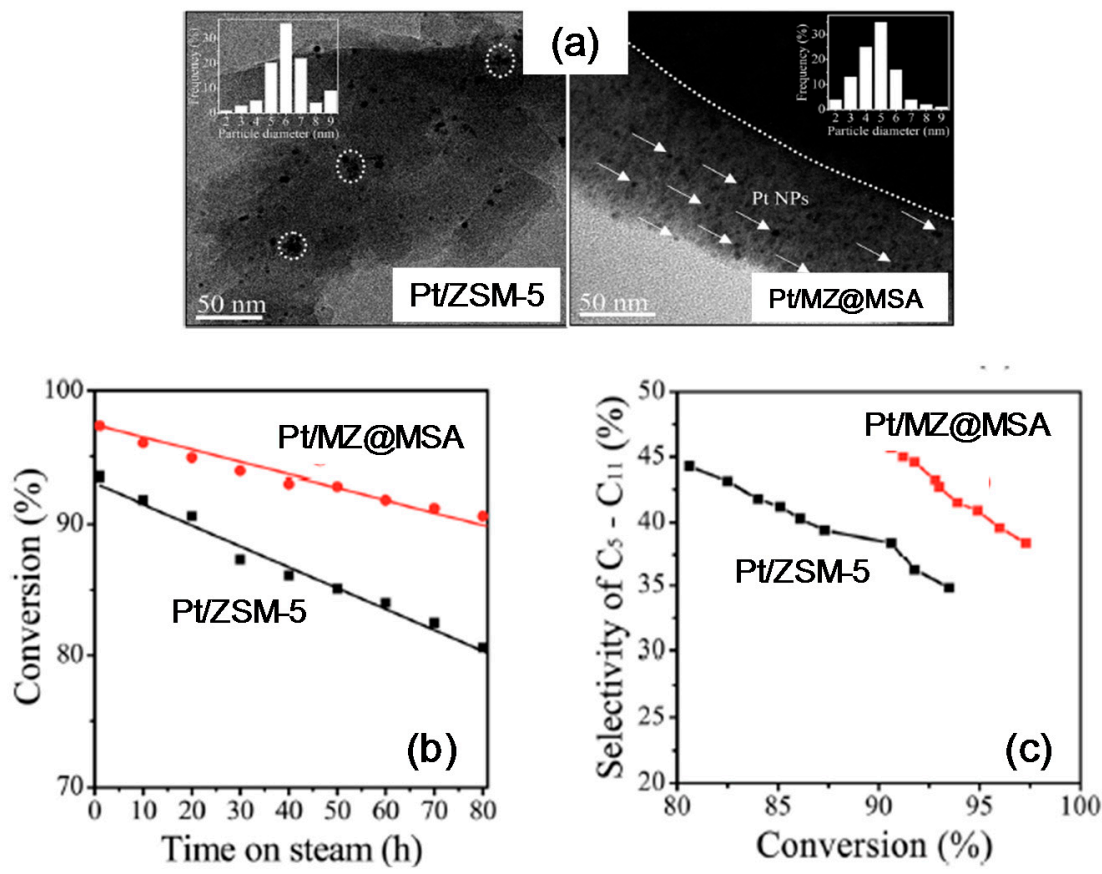

Figure 16. (a) HRTEM images of Pt/ZSM-5 and Pt/MZ@MSA catalysts; the insets depict the size distribution of Pt nanoparticles (NPs); (b) The conversion of n-hexadecane with time-on-stream and (c) the selectivity to $\mathrm{C}_{5}-\mathrm{C}_{10}$ hydrocarbons as a function of the conversion in the hydrocracking of n-hexadecane over Pt/ZSM-5 and Pt/MZ@MSA catalysts. Adapted with permission from [68]. Copyright Royal Society of Chemistry, 2014. 
Hydroisomerization of linear alkanes is widely employed to transform light naphtha fractions, i.e., $\mathrm{C}_{5}-\mathrm{C}_{6}$ cuts into high octane gasoline components. However, when going to longer chain alkanes, the application of zeolites is hindered because of severe diffusion limitations. In this respect, the metal supported MZC catalysts are among the most perspective catalysts for hydroisomerization of $n$-alkanes with more than six carbon atoms due to their ability to improve the metal distribution and alleviate the diffusion constraints [28,40,59,72,100-102]. An excellent example was given by Konnov et al. [72] who studied the hydroisomerization of $n$-alkanes with different chain lengths over composite supported Pt catalysts (Pt/RMOR) (Figure 17).

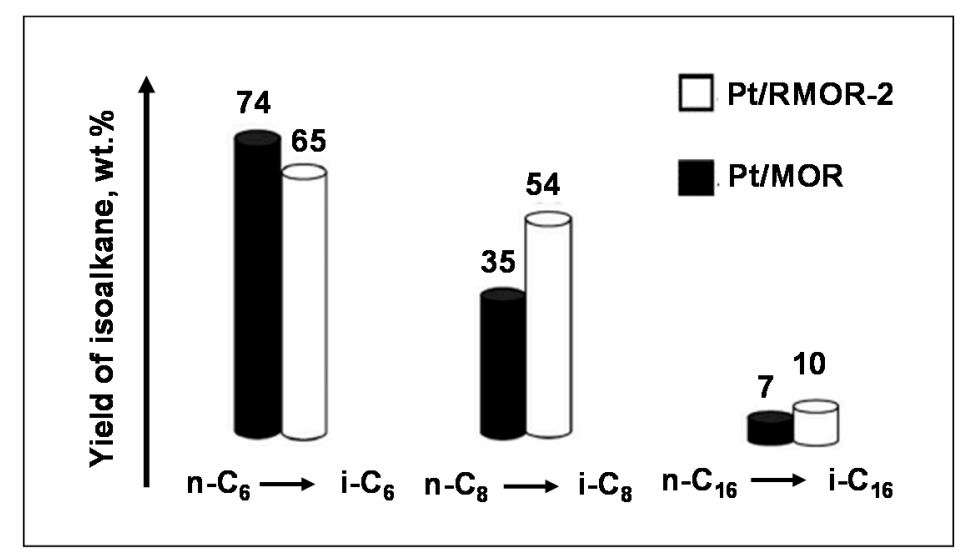

Figure 17. The yields for iso-alkanes in the hydroisomerization of $n$-hexanes $\left(C_{6}\right), n$-octanes $\left(C_{8}\right)$ and $n$-hexadecanes $\left(\mathrm{C}_{16}\right)$ over the $\mathrm{Pt} /$ recrystallized composite (RMOR-2) relative to the parent MOR. Adapted with permission from [28]. Copyright Royal Society of Chemistry, 2013.

The composite supports comprising mordenite (MOR) crystals coated by MCM- 41 phase were prepared by recrystallization of MOR using $\mathrm{NaOH}$ treatment and subsequent self-assembly with assistance of the CTAB template. The catalytic tests show that the hydroisomerization of $n$-hexane occurs without significant diffusion limitations; thus the Pt/RMOR gives a lower yield of iso-hexanes than $\mathrm{Pt} / \mathrm{MOR}$. For $n$-octane with a medium long hydrocarbon chain, a remarkably higher yield of iso-octanes is observed over $\mathrm{Pt} / \mathrm{RMOR}$ in relation to $\mathrm{Pt} / \mathrm{MOR}$. The enhancement can be assigned to improved molecular transport and accessibility of acid sites, and the optimized Pt particle size induced by the hierarchical porous system of the composite support RMOR. On the other hand, when transforming larger alkanes such as n-hexadecane, a slight increase in the yield of iso-hexadecanes was obtained over $\mathrm{Pt} / \mathrm{RMO}$ with respect to $\mathrm{Pt} / \mathrm{MOR}$. This is attributed to the increased selectivity regulated by $\mathrm{Pt}$ particle sizes since $n$-hexadecanes cannot enter the pores of zeolites and are mainly converted on the external surface.

\section{Conclusions and Outlook}

Micro/mesoporous zeolitic composites (MZCs) have emerged as an important class of catalytic materials. In MZCs, zeolite domains hold the major fraction of active sites, and their accessibility is enhanced by the mesoporous phase serving as a composite partner. Thus, the advantages of mesoporous materials and zeolites can be combined to create superior MZC materials. The present review discussed the recent advances on MZC materials with special focus on the synthesis methods and catalytic applications. To illustrate state-of-the-art achievement in the field, we showed prominent examples of the different routes available to prepare MZCs. Among the three main synthesis approaches, the direct synthesis using zeolite precursors and the recrystallization of zeolites have been extensively investigated over a wide range of zeolites and mesoporous materials; thus providing a versatile tool for the preparation of MZCs. Although several studies have focused on zeolitization of preformed mesoporous materials, the application of this third method is rather limited due to the complicated synthesis procedure and destruction of parent mesostructures. Nevertheless, 
it should be stressed that each method has its own advantages and disadvantages and the selection of a particular method for preparation of MZCs should be based on the structural, textural and functional requirements of the targeted catalytic reactions.

Catalytic applications of MZCs have been tested in different industrially relevant reactions namely catalytic cracking, alkylation of aromatics, methanol-to-hydrocarbon reactions, and hydroconversions. In most cases, MZC catalysts display superior catalytic activity, selectivity, and life time with respect to conventional zeolites and mesoporous materials and the mixture thereof. The improved catalytic performance of MZC catalysts is generally attributed to enhanced molecular transport and accessibility of active sites provided by the inter-connected porous system while retaining the intrinsic catalytic properties of zeolites. Furthermore, the loading of active metals in MZCs results in excellent bifunctional catalysts for hydroconversion processes as evidenced by studies on hydrodesulfurization, hydroisomerization and hydrocracking. With the larger surface areas and confined effect of the mesoporous part, MZCs allow a better metal distribution than pristine zeolites. Thus, the combination of the advantages of the intrinsic properties of zeolites, the improved molecular transport inside mesoporous materials, and the additional function of metal active sites generates superior catalytic performance of MZC catalysts in hydroconversion reactions.

Despite notable progress in the synthesis and catalytic applications of MZCs, significant challenges are still ahead. The overall one is the development of synthesis methods that are easy to perform, capable of tuning the distribution of microporous zeolites and mesoporous materials, and offering the possibility to scale-up in a cost-effective way. In the design of MZCs, a suitable balance between microporous and mesoporous phases is of vital importance. Thus, future efforts should focus on more precise control over this ratio while ensuring the interconnection of the microporous framework with the mesostructure to maximize benefits of the hierarchical bimodal porous system. In this respect, the systematical investigation of the impact of the synthesis conditions on product properties is required. A better understanding of the formation mechanism of MZCs during synthesis would be also beneficial. Additionally, the development of tailored descriptors for MZCs might be helpful in characterizing and correlating the structural property and materials performance of MZCs. More credit should be paid to the interaction between the microporous and mesoporous phases and their role in the catalyzed reactions. Such knowledge about the interaction between two phases would help to improve the synthesis and catalytic performance of MZCs. Hence, future works should be devoted to the profound analysis of the structure, chemical composition, location, and nature of acid sites of the microporous and mesoporous phases in MZCs. Although the improved catalytic performance of MZCs is generally attributed to the enhanced molecular transport, most of the time no direct evidence of diffusion characteristics is given. Accordingly, depth diffusion studies on MZCs should be conducted to evidence the advantages of the hierarchical porous system of MZCs. Since large scale synthesis of MZCs desires the use of low cost mesostructured templates that should preferably be sustainable or readily recyclable, and here bio-polymers seem to be an attractive option. In addition, scale-up demonstration clearly requires more effort for transition from laboratory synthesis scale to plant scale. Finally, from the catalytic application point of view, there is still ample room for MZC materials, both in existing zeolite catalyzed processes and emerging catalytic applications.

Acknowledgments: X.H.V. thanks Ton Duc Thang University for the financial support.

Author Contributions: X.H.V., U.A. and A.M. designed the review structure, X.H.V. wrote the first draft, X.H.V., U.A. and A.M. iteratively brought it to its final state.

Conflicts of Interest: The authors declare no conflict of interest.

\section{References}

1. McCusker, L.B.; Baerlocher, C. Zeolite structures. In Introduction to Zeolite Science and Practice, 2nd ed.; Jacobs, P.A., Flanigen, E.M., Jansen, J.C., van Bekkum, H., Eds.; Elsevier Science Publisher: Amsterdam, The Netherlands, 2001; Volume 137, pp. 37-67. 
2. International Zeolite Association Database, 2006. Available online: http://www.iza-structure.org/database (accessed on 20 October 2016).

3. Corma, A. State of the art and future challenges of zeolites as catalysts. J. Catal. 2003, 216, 298-312. [CrossRef]

4. Vogt, E.T.C.; Weckhuysen, B.M. Fluid catalytic cracking: Recent developments on the grand old lady of zeolite catalysis. Chem. Soc. Rev. 2015, 44, 7342-7370. [CrossRef] [PubMed]

5. Parlett, C.M.A.; Wilson, K.; Lee, A.F. Hierarchical porous materials: Catalytic applications. Chem. Soc. Rev. 2013, 42, 3876-3893. [CrossRef] [PubMed]

6. Li, K.; Valla, J.; Garcia-Martinez, J. Realizing the commercial potential of hierarchical zeolites: New opportunities in catalytic cracking. Chem CatChem 2014, 6, 46-66. [CrossRef]

7. Shi, J.; Wang, Y.; Yang, W.; Tang, Y.; Xie, Z. Recent advances of pore system construction in zeolite-catalyzed chemical industry processes. Chem. Soc. Rev. 2015, 44, 8877-8903. [CrossRef] [PubMed]

8. Hartmann, M.; Machoke, A.G.; Schwieger, W. Catalytic test reactions for the evaluation of hierarchical zeolites. Chem. Soc. Rev. 2016, 45, 3313-3330. [CrossRef] [PubMed]

9. Chal, R.; Gérardin, C.; Bulut, M.; van Donk, S. Overview and industrial assessment of synthesis strategies towards zeolites with mesopores. ChemCatChem 2011, 3, 67-81. [CrossRef]

10. Pérez-Ramírez, J.; Christensen, C.H.; Egeblad, K.; Christensen, C.H.; Groen, J.C. Hierarchical zeolites: Enhanced utilisation of microporous crystals in catalysis by advances in materials design. Chem. Soc. Rev. 2008, 37, 2530-2542. [CrossRef] [PubMed]

11. Malgras, V.; Ji, Q.; Kamachi, Y.; Mori, T.; Shieh, F.K.; Wu, K.C.W.; Ariga, K.; Yamauchi, Y. Templated synthesis for nanoarchitectured porous materials. Bull. Chem. Soc. Jpn. 2015, 88, 1171-1200. [CrossRef]

12. Wu, K.C.W.; Yamauchi, Y. Controlling physical features of mesoporous silica nanoparticles (MSNs) for emerging applications. J. Mater. Chem. 2012, 22, 1251-1256. [CrossRef]

13. Čejka, J.; Mintova, S. Perspectives of Micro/mesoporous composites in catalysis. Catal. Rev. Sci. Eng. 2007, 49, 457-509. [CrossRef]

14. Liu, Y.; Pinnavaia, T.J. Aluminosilicate mesostructures with improved acidity and hydrothermal stability. J. Mater. Chem. 2002, 12, 3179-3190.

15. Vu, X.H.; Steinfeldt, N.; Armbruster, U.; Martin, A. Improved hydrothermal stability and acidic properties of ordered mesoporous SBA-15 analogs assembled from nanosized ZSM-5 precursors. Microporous Mesoporous Mater. 2012, 164, 120-126. [CrossRef]

16. Schwieger, W.; Machoke, A.G.; Weissenberger, T.; Inayat, A.; Selvam, T.; Klumpp, M.; Inayat, A. Hierarchy concepts: Classification and preparation strategies for zeolite containing materials with hierarchical porosity. Chem. Soc. Rev. 2016, 45, 3353-3376. [CrossRef] [PubMed]

17. Lopez-Orozco, S.; Inayat, A.; Schwab, A.; Selvam, T.; Schwieger, W. Zeolitic materials with hierarchical porous structures. Adv. Mater. 2011, 23, 2602-2615. [CrossRef] [PubMed]

18. Möller, K.; Bein, T. Mesoporosity-A new dimension for zeolites. Chem. Soc. Rev. 2013, 42, 3689-3707.

19. Verboekend, D.; Nuttens, N.; Locus, R.; Van Aelst, J.; Verolme, P.; Groen, J.C.; Pérez-Ramírez, J.; Selsa, B.F. Synthesis, characterisation, and catalytic evaluation of hierarchical faujasite zeolites: Milestones, challenges, and future directions. Chem. Soc. Rev. 2016, 45, 3331-3352. [CrossRef] [PubMed]

20. Valtchev, V.; Majano, G.; Mintova, S.; Pérez-Ramírez, J. Tailored crystalline microporous materials by post-synthesis modification. Chem. Soc. Rev. 2013, 42, 263-290. [CrossRef] [PubMed]

21. Serrano, D.P.; Escola, J.M.; Pizarro, P. Synthesis strategies in the search for hierarchical zeolites. Chem. Soc. Rev. 2013, 42, 4004-4035. [PubMed]

22. Egeblad, K.; Christensen, C.H.; Kustova, M.; Christensen, C.H. Templating Mesoporous Zeolites. Chem. Mater. 2008, 20, 946-960. [CrossRef]

23. Na, K.; Choi, M.; Ryoo, R. Recent advances in the synthesis of hierarchically nanoporous zeolites. Microporous Mesoporous Mater. 2013, 166, 3-19. [CrossRef]

24. Zhang, K.; Ostraat, M.L. Innovations in hierarchical zeolite synthesis. Catal. Today 2016, 264, 3-15. [CrossRef]

25. Yan, Y.; Guo, X.; Zhang, Y.; Tang, Y. Future of nano-/hierarchical zeolites in catalysis: Gaseous phase or liquid phase system. Catal. Sci. Technol. 2015, 5, 772-785. [CrossRef]

26. Hua, Z.L.; Zhou, J.; Shi, J.L. Recent advances in hierarchically structured zeolites: Synthesis and material performances. Chem. Commun. 2011, 47, 10536-10547. [CrossRef] [PubMed] 
27. Chen, L.H.; Li, X.Y.; Rooke, J.C.; Zhang, Y.H.; Yang, X.Y.; Tang, Y.; Xiao, F.S.; Su, B.L. Hierarchically structured zeolites: Synthesis, mass transport properties and applications. J. Mater. Chem. 2012, 22, 17381-17403. [CrossRef]

28. Ivanova, I.I.; Knyazeva, E.E. Micro-mesoporous materials obtained by zeolite recrystallization: Synthesis, characterization and catalytic applications. Chem. Soc. Rev. 2013, 42, 3671-3688. [CrossRef] [PubMed]

29. Prasomsri, T.; Jiao, W.; Weng, S.Z.; Martinez, J.G. Mesostructured zeolites: Bridging the gap between zeolites and MCM-41. Chem. Commun. 2015, 51, 8900-8911. [CrossRef] [PubMed]

30. Liu, Y.; Zhang, W.; Pinnavaia, T.J. Steam-stable aluminosilicate mesostructures assembled from zeolite type Y seeds. J. Am. Chem. Soc. 2000, 122, 8791-8792. [CrossRef]

31. Waller, P.; Shan, Z.; Marchese, L.; Tartaglione, G.; Zhou, W.; Jansen, J.C.; Maschmeyer, T. Zeolite nanocrystals inside mesoporous TUD-1: A high-performance catalytic composite. Chem. Eur. J. 2004, 10, 4970-4976. [CrossRef] [PubMed]

32. Li, P.; Xiong, G.; Liu, L.; Wang, L. Investigation on the effect of zeolite precursor on the formation process of MCM-41 containing zeolite Y building units. Spectrochim. Acta Part. A: Mol. Biomol. Spectrosc. 2013, 107, 218-226. [CrossRef] [PubMed]

33. Xia, Y.; Mokaya, R. On the synthesis and characterization of ZSM-5/MCM-48 aluminosilicate composite materials. J. Mater. Chem. 2004, 14, 863-870. [CrossRef]

34. Xia, Y.; Mokaya, R. Are mesoporous silicas and aluminosilicas assembled from zeolite seeds inherently hydrothermally stable? Comparative evaluation of MCM-48 materials assembled from zeolite seeds. J. Mater. Chem. 2004, 14, 3427-3435. [CrossRef]

35. Huo, Q.; Gong, Y.; Dou, T.; Zhao, Z.; Pan, H.; Deng, F. Novel micro- and mesoporous composite molecular sieve assembled by zeolite L nanocrystal and its performance for the hydrodesulfurization (HDS) of fluidized catalytic cracking (FCC) gasoline. Energy Fuels 2010, 24, 3764-3771. [CrossRef]

36. Du, P.; Zheng, P.; Song, S.; Wang, X.; Zhang, M.; Chi, K.; Xu, C.; Duan, A.; Zhao, Z. Synthesis of a novel micro/mesoporous composite material Beta-FDU-12 and its hydro-upgrading performance for FCC gasoline. RSC Adv. 2016, 6, 1018-1026. [CrossRef]

37. Gao, A.; Duan, A.; Zhang, X.; Chi, K.; Zhao, Z.; Li, J.; Qin, Y.; Wang, X.; Xu, C. Self-assembly of monodispersed hierarchically porous Beta-SBA-15 with different morphologies and their hydro-upgrading performances of FCC gasoline. J. Mater. Chem. A 2015, 3, 16501-16512. [CrossRef]

38. Di, Z.; Yang, C.; Jiao, X.; Li, J.; Wu, J.; Zhang, D. A ZSM-5/MCM-48 based catalyst for methanol to gasoline conversion. Fuel 2013, 104, 878-881. [CrossRef]

39. Ooi, Y.S.; Zakaria, R.; Mohamed, A.R.; Bhatia, S. Synthesis of composite material MCM-41/Beta and its catalytic performance in waste used palm oil cracking. Appl. Catal. A: Gen. 2004, 274, 15-23. [CrossRef]

40. Tang, W.; Zhang, H.; Lu, Y.; Yao, Y.; Lu, S. Two-step hydrothermal synthesis of beta-MCM-41 composite molecular sieves as supports of bifunctional catalysts for hydroisomerization of n-heptane. J. Porous Mater. 2016. [CrossRef]

41. Vu, X.H.; Bentrup, U.; Hunger, M.; Kraehnert, R.; Armbruster, U.; Martin, A. Direct synthesis of nanosized-ZSM-5/SBA-15 analog composites from preformed ZSM-5 precursors for improved catalytic performance as cracking catalyst. J. Mater. Sci. 2014, 49, 5676-5689. [CrossRef]

42. Xue, B.; Xu, J.; Xu, C.; Wu, R.; Li, Y.; Zhang, K. A novel, shape-selective H-MCM-22/MCM-41 composite catalyst: Synthesis, characterization and catalytic performance. Catal. Commun. 2010, 12, 95-99. [CrossRef]

43. Qian, X.; Du, J.; Li, B.; Si, M.; Yang, Y.; Hu, Y.; Niu, G.; Zhang, Y.; Xu, H.; Tu, B.; et al. Controllable fabrication of uniform core-shell structured zeolite@SBA-15 composites. Chem. Sci. 2011, 2, 2006-2016. [CrossRef]

44. Lima, S.; Antunes, M.M.; Fernandes, A.; Pillinger, M.; Ribeiro, M.F.; Valente, A.A. Catalytic cyclodehydration of xylose to furfural in the presence of zeolite H-Beta and a micro/mesoporous Beta/TUD-1 composite material. Appl. Catal. A: Gen. 2010, 388, 141-148. [CrossRef]

45. Prokešová, P.; Žilková, N.; Mintova, S.; Bein, T.; Čejka, J. Catalytic activity of micro/mesoporous composites in toluene alkylation with propylene. Appl. Catal. A: Gen. 2005, 281, 85-91. [CrossRef]

46. Wang, Y.; Cui, D.; Li, Q. Synthesis, characterization and influence parameters on the overgrowth of micro/mesoporous Y-zeolite-MCM-41 composite material under acidic conditions. Microporous Mesoporous Mater. 2011, 142, 503-510. [CrossRef] 
47. Enterría, M.; Suárez-García, F.; Martínez-Alonso, A.; Tascón, J.M.D. Preparation of hierarchical micro-mesoporous aluminosilicate composites by simple Y zeolite/MCM-48 silica assembly. J. Alloys Compd. 2014, 583, 60-69. [CrossRef]

48. Zhang, Y.; Liu, Y.; Li, Y. Synthesis and characteristics of Y-zeolite/MCM-48 biporous molecular sieve. Appl. Catal. A: Gen. 2008, 345, 73-79.

49. Wei, L.; Zhang, H.; Dong, Y.; Song, W.; Liu, X.; Zhao, Z. Synthesis and characterization of MCM-49/MCM-41 composite molecular sieve: An effective adsorbent for chromate from water. RSC Adv. 2016, 6, 71375-71383. [CrossRef]

50. Goto, Y.; Fukushima, Y.; Ratu, P.; Imada, Y.; Kubota, Y.; Sugi, Y.; Ogura, M.; Matsukata, M. Mesoporous material from zeolite. J. Porous Mater. 2002, 9, 43-48. [CrossRef]

51. Ivanova, I.I.; Kuznetsov, A.S.; Knyazeva, E.E.; Fajula, F.; Thibault-Starzyk, F.; Fernandez, C.; Gilson, J.P. Design of hierarchically structured catalysts by mordenites recrystallization: Application in naphthalene alkylation. Catal. Today 2011, 168, 133-139. [CrossRef]

52. Ponomareva, O.A.; Timoshin, C.E.; Monakhova, Y.V.; Knyazeva, E.E.; Yuschenko, V.V.; Ivanova, I.I. Benzene Alkylation with Dodecene_1 over Micro-Mesoporous Molecular Sieves. Pet. Chem. 2010, 50, 427-436. [CrossRef]

53. Jiao, W.Q.; Ding, J.; Shi, Z.B.; Liang, X.M.; Wang, Y.M.; Zhang, Y.H.; Tang, Y.; He, M.Y. Preparation of Y zeolite composites with adjustable, highly dispersed intra-crystal mesoporosity: Effect of lactic acid treatment in CTAB-assisted two-step approach. Microporous Mesoporous Mater. 2016, 228, 237-247. [CrossRef]

54. Liu, X.; Yang, T.; Bai, P.; Han, L. Y/MCM-41 composites assembled from nanocrystals. Microporous Mesoporous Mater. 2011, 2, 2006-2016. [CrossRef]

55. Sang, Y.; Liu, H.; He, S.; Li, H.; Jiao, Q.; Wu, Q.; Sun, K. Catalytic performance of hierarchical H-ZSM-5/MCM-41 for methanol dehydration to dimethyl ether. J. Energy Chem. 2013, 22, 769-777. [CrossRef]

56. Peng, P.; Wang, Y.; Zhang, Z.; Qiao, K.; Liu, X.; Yan, Z.; Subhan, F.; Komarneni, S. ZSM-5-based mesostructures by combined alkali dissolution and re-assembly: Process controlling and scale-up. Chem. Eng. J. 2016, 302, 323-333. [CrossRef]

57. Boukoussa, B.; Aouad, N.; Hamacha, R.; Bengueddach, A. Key factor affecting the structural and textural properties of ZSM-5/MCM-41 composite. J. Phys. Chem. Solids 2015, 78, 78-83. [CrossRef]

58. Ivanova, I.I.; Kasyanov, I.A.; Maerle, A.A.; Zaikovskii, V.I. Mechanistic study of zeolites recrystallization into micro-mesoporous materials. Microporous Mesoporous Mater. 2014, 189, 163-172. [CrossRef]

59. Liu, S.; Ren, J.; Zhang, H.; Lv, E.; Yang, Y.; Li, Y.W. Synthesis, characterization and isomerization performance of micro/mesoporous materials based on H-ZSM-22 zeolite. J. Catal. 2016, 335, 11-23. [CrossRef]

60. Ponomareva, O.A.; Mal'tseva, A.A.; Maerle, A.A.; Rodionova, L.I.; Pavlov, V.S.; Dobryakova, I.V.; Belova, M.V.; Ivanova, I.I. Production of isobutylene from acetone over micro-mesoporous catalysts. Pet. Chem. 2016, 56, 253-258. [CrossRef]

61. Verboekend, D.; Milina, M.; Mitchell, S.; Pérez-Ramírez, J. Hierarchical zeolites by desilication: Occurrence and catalytic impact of recrystallization and restructuring. Cryst. Growth Des. 2013, 13, 5025-5035. [CrossRef]

62. Diao, Z.; Wang, L.; Zhang, X.; Liu, G. Catalytic cracking of supercritical n-dodecane over meso-HZSM-5 ${ }^{\circledR}$ Al-MCM-41 zeolites. Chem. Eng. Sci. 2015, 135, 452-460. [CrossRef]

63. Yoo, W.C.; Zhang, X.; Tsapatsis, M.; Stein, A. Synthesis of mesoporous ZSM-5 zeolites through desilication and re-assembly processes. Microporous Mesoporous Mater. 2012, 149, 147-157. [CrossRef]

64. Li, G.; Diao, Z.; Na, J.; Wang, L. Exploring suitable ZSM-5/MCM-41 zeolites for catalytic cracking of n-dodecane: Effect of initial particle size and Si/Al ratio. Chin. J. Chem. Eng. 2015, 23, 1655-1661. [CrossRef]

65. Gao, N.; Xie, S.; Liu, S.; An, J.; Zhu, X.; Hu, L.; Wei, H.; Li, X.; Xu, L. Catalytic degradation of LDPE and PP over MCM-49 based micro-mesoporous composites. Catal. Lett. 2014, 144, 1296-1304. [CrossRef]

66. Peng, P.; Wang, Y.; Rood, M.J.; Zhang, Z.; Subhan, F.; Yan, Z.; Qin, L.; Zhang, Z.; Zhang, Z.; Gao, X. Effects of dissolution alkalinity and self-assembly on ZSM-5-based micro-/mesoporous composites: A study of the relationship between porosity, acidity, and catalytic performance. Cryst. Eng. Comm. 2015, 17, 3820-3828. [CrossRef]

67. Kasyanov, I.A.; Maerle, A.A.; Ivanova, I.I.; Zaikovskii, V.I. Towards understanding of the mechanism of stepwise zeolite recrystallization into micro/mesoporous materials. J. Mater. Chem. A 2014, 2, 16978-16988. [CrossRef] 
68. Wang, D.; Xu, L.; Wu, P. Hierarchical, core-shell meso-ZSM-5@mesoporous aluminosilicate-supported Pt nanoparticles for bifunctional hydrocracking. J. Mater. Chem. A 2014, 2, 15535-15545. [CrossRef]

69. Ren, B.; Bai, S.; Sun, J.; Zhang, F.; Fan, M. Controllable synthesis of obvious core-shell structured Y/Beta composite zeolite by a stepwise-induced method. RSC Adv. 2014, 4, 22755-22758. [CrossRef]

70. Odedairo, T.; Balasamy, R.J.; Al-Khattaf, S. Aromatic transformations over aluminosilicate micro/mesoporous composite materials. Catal. Sci. Technol. 2012, 2, 1275-1286. [CrossRef]

71. Li, Y.; Zhang, W.; Wang, X.; Zhang, Y.; Dou, T.; Xie, K. Synthesis, characterization, and catalytic properties of a hydrothermally stable Beta/MCM-41 composite from well-crystallized zeolite Beta. J. Porous Mater. 2008, 15, 133-138. [CrossRef]

72. Konnov, S.V.; Ivanova, I.I.; Ponomareva, O.A.; Zaikovskii, V.I. Hydroisomerization of n-alkanes over Pt-modified micro/mesoporous materials obtained by mordenite recrystallization. Microporous Mesoporous Mater. 2012, 164, 222-231. [CrossRef]

73. Kloetstra, K.R.; van Bekkum, H.; Jansen, J.C. Mesoporous material containing framework tectosilicate by pore-wall recrystallization. Chem. Commun. 1997, 22, 2281-2282. [CrossRef]

74. Verhoef, M.J.; Kooyman, P.J.; van der Waal, J.C.; Rigutto, M.S.; Peters, J.A.; van Bekkum, H. Partial Transformation of MCM-41 material into zeolites: Formation of nanosized MFI type crystallites. Chem. Mater. 2001, 13, 683-687. [CrossRef]

75. Chen, H.L.; Zhang, K.; Wang, Y.M. Steam-assisted crystallization of TPA ${ }^{+}$-exchanged MCM-41 type mesoporous materials with thick pore walls. Mater. Res. Bull. 2012, 47, 1774-1782. [CrossRef]

76. Huang, L.; Guo, W.; Deng, P.; Xue, Z.; Li, Q. Investigation of Synthesizing MCM-41/ZSM-5 Composites. J. Phys. Chem. B 2000, 104, 2817-2823. [CrossRef]

77. Campos, A.A.; Dimitrov, L.; da Silva, C.R.; Wallau, M.; Urquieta-González, E.A. Recrystallisation of mesoporous SBA-15 into microporous ZSM-5. Microporous Mesoporous Mater. 2006, 95, 92-103. [CrossRef]

78. On, D.T.; Kaliaguine, S. Large-pore mesoporous materials with semicrystalline zeolitic frameworks. Angew. Chem. Int. Ed. 2001, 40, 3248-3251.

79. Wang, J.; Groen, J.C.; Yue, W.; Zhou, W.; Coppens, M.O. Single-template synthesis of zeolite ZSM-5 composites with tunable mesoporosity. J. Mater. Chem. 2008, 18, 468-474. [CrossRef]

80. Wang, J.; Yue, W.; Zhou, W.; Coppens, M.O. TUD-C: A tunable, hierarchically structured mesoporous zeolite composite. Microporous Mesoporous Mater. 2009, 120, 19-28. [CrossRef]

81. Zhou, J.; Hua, Z.; Zhao, J.; Gao, Z.; Zeng, S.; Shi, J. A micro/mesoporous aluminosilicate: Key factors affecting framework crystallization during steam-assisted synthesis and its catalytic property. J. Mater. Chem. 2010, 20, 6764-6771. [CrossRef]

82. Ogura, M.; Inoue, K.; Yamaguchi, T. A mechanistic study on the synthesis of MCM-22 from SBA-15 by dry gel conversion to form a micro- and mesoporous composite. Catal. Today 2011, 168, 118-123. [CrossRef]

83. Koekkoek, A.J.J.; Degirmenci, V.; Hensen, E.J.M. Dry gel conversion of organosilane templated mesoporous silica: From amorphous to crystalline catalysts for benzene oxidation. J. Mater. Chem. 2011, 21, 9279-9289. [CrossRef]

84. Pashkova, V.; Włoch, E.; Mikołajczyk, A.; Łaniecki, M.; Sulikowski, B.; Derewinski, M. Composite SBA-15/MFI type materials: Preparation, characterization and catalytic performance. Catal. Lett. 2009, 128, 64-71. [CrossRef]

85. Vu, X.H.; Nguyen, S.; Dang, T.T.; Phan, B.M.Q.; Nguyen, D.A.; Armbruster, U.; Martin, A. Catalytic cracking of triglyceride-rich biomass toward lower olefins over a nano-ZSM-5/SBA-15 analog composite. Catalysts 2015, 5, 1692-1703. [CrossRef]

86. Bagshaw, S.A.; Baxter, N.I.; Brew, D.R.M.; Hosie, C.F.; Yuntong, N.; Jaenicke, S.; Khuan, C.G. Highly ordered mesoporous MSU-S $\mathrm{BEA}$ /zeolite Beta composite material. J. Mater. Chem. 2006, 16, 2235-2244. [CrossRef]

87. Morales-Pacheco, P.; Domínguez, J.M.; Bucio, L.; Alvarez, F.; Sedran, U.; Falco, M. Synthesis of FAU(Y)and MFI(ZSM5)-nanosized crystallites for catalytic cracking of 1,3,5-triisopropylbenzene. Catal. Today 2011, 166, 25-38.

88. Frunz, L.; Prins, R.; Pirngruber, G.D. ZSM-5 precursors assembled to a mesoporous structure and its subsequent transformation into a zeolitic phase-from low to high catalytic activity. Microporous Mesoporous Mater. 2006, 88, 152-162. [CrossRef] 
89. Aghakhani, M.S.; Khodadadi, A.A.; Najafi, Sh.; Mortazavi, Y. Enhanced triisopropylbenzene cracking and suppressed coking on tailored composite of Y-zeolite/amorphous silica-alumina catalyst. J. Ind. Eng. Chem. 2014, 20, 3037-3045. [CrossRef]

90. Coriolano, A.C.F.; Silva, C.G.C.; Costa, M.J.F.; Pergher, S.B.C.; Caldeira, V.P.S.; Araujo, A.S. Development of HZSM-5/AlMCM-41 hybrid micro-mesoporous material and application for pyrolysis of vacuum gasoil. Microporous Mesoporous Mater. 2013, 72, 206-212. [CrossRef]

91. Banu, M.; Lee, Y.H.; Magesh, G.; Nam, C.-M.; Lee, J.S. MOR/SBA-15 composite catalysts with interconnected meso/micropores for improved activity and stability in isopropylation of naphthalene. ChemCatChem 2015, 7, 2354-2360. [CrossRef]

92. Lee, Y.H.; Kim, W.Y.; Park, H.; Choi, Y.H.; Lee, J.S. Highly active and coke-tolerant hierarchical mordenite catalysts synthesized by recrystallization for the isopropylation of naphthalene. ChemCatChem 2016, 8, 2996-3001. [CrossRef]

93. Song, K.; Guan, J.; Wu, S.; Yang, Y.; Liu, B.; Kan, Q. Alkylation of phenol with tert-butanol catalyzed by mesoporous material with enhanced acidity synthesized from zeolite MCM-22. Catal. Lett. 2008, 126, 333-340. [CrossRef]

94. Wu, H.; Duan, A.; Zhao, Z.; Li, T.; Prins, R.; Zhou, X. Synthesis of NiMo hydrodesulfurization catalyst supported on a composite of nano-sized ZSM-5 zeolite enwrapped with mesoporous KIT- 6 material and its high isomerization selectivity. J. Catal. 2014, 317, 303-317. [CrossRef]

95. Zhang, D.; Duan, A.; Zhao, Z.; Xu, C. Synthesis, characterization, and catalytic performance of NiMo catalysts supported on hierarchically porous Beta-KIT-6 material in the hydrodesulfurization of dibenzothiophene. J. Catal. 2010, 274, 273-286. [CrossRef]

96. Qin, B.; Zhang, X.; Zhang, Z.; Ling, F.; Sun, W. Synthesis, characterization and catalytic properties of Y- $\beta$ zeolite composites. Pet. Sci. 2011, 8, 224-228. [CrossRef]

97. Zhang, X.W.; Guo, Q.; Qin, B.; Zhang, Z.; Ling, F.; Sun, W.; Li, R. Structural features of binary microporous zeolite composite Y-beta and its hydrocracking performance. Catal. Today 2010, 149, 212-217. [CrossRef]

98. Chen, S.; Yang, Y.; Zhang, K.; Wang, J. BETA zeolite made from mesoporous material and its hydrocracking performance. Catal. Today 2006, 116, 2-5. [CrossRef]

99. Busse, O.; Räuchle, K.; Reschetilowski, W. Hydrocracking of ethyl laurate on bifunctional micro-/mesoporous zeolite catalysts. ChemSusChem 2010, 3, 563-565. [CrossRef] [PubMed]

100. Konnov, S.V.; Sushkevich, V.L.; Monachova, Y.V.; Yushcenko, V.V.; Ponomareva, O.A.; Ivanova, I.I. Hydroisomerization of $n$-Octane over Pt-containing micro/mesoporous molecular sieves. Stud. Surf. Sci. Catal. 2008, 174, 1167-1170.

101. Liu, P.; Yao, Y.; Wang, J. Using beta-MCM41 composite molecular sieves as supports of bifunctional catalysts for the hydroisomerization of n-heptane. React. Kinet. Mech. Catal. 2010, 101, 465-475. [CrossRef]

102. Paixão, V.; Santos, C.; Nunes, R.; Silva, J.M.; Pires, J.; Carvalho, A.P.; Martins, A. n-Hexane hydroisomerization over composite catalysts based on beta zeolite and mesoporous materials. Catal. Lett. 2009, 129, 331-335. [CrossRef]

(C) 2016 by the authors; licensee MDPI, Basel, Switzerland. This article is an open access article distributed under the terms and conditions of the Creative Commons Attribution (CC-BY) license (http://creativecommons.org/licenses/by/4.0/). 